\title{
Political Business Cycles in the New Keynesian Model*
}

\author{
Fabio Milani \\ University of California, Irvine
}

November 13, 2007

\author{
[Comments Welcome]
}

\begin{abstract}
This paper tests various Political Business Cycle theories in a New Keynesian model with a monetary and fiscal policy mix. All the policy coefficients, the target levels of inflation and the budget deficit, the firms' frequency of price setting, and the standard deviations of the structural shocks are allowed to depend on 'political' regimes: a preelection vs. post-election regime, a regime that depends on whether the President (or the Fed Chairman) is a Democrat or a Republican, and a regime under which the President and the Fed Chairman share party affiliation in pre-election quarters or not.

The model is estimated using full-information Bayesian methods. The assumption of rational expectations is relaxed: economic agents can learn about the effect of political variables over time.

The results provide evidence that several coefficients depend on political variables. The best-fitting specification is one that allows coefficients to depend on a pre-election vs. non-election regime. Monetary policy becomes considerably more inertial before elections and fiscal policy deviations from a simple rule are more common. The results overall support the view of an independent Fed that avoids taking policy decisions right before elections. There is some evidence, however, that policies become more expansionary before elections, but this evidence seems to disappear in the post-1985 sample. The estimates also indicate that firms similarly delay their price-setting decisions until after the upcoming Presidential election.
\end{abstract}

Keywords: Political Business Cycles, Opportunistic Cycles, Partisan Cycles, Monetary and Fiscal Policy, Adaptive Learning, Bayesian Estimation.

JEL classification: C11, D72, E32, E52, E58, E63.

${ }^{*}$ I would like to thank Michelle Garfinkel, Ami Glazer, and Burt Abrams for comments. Address for correspondence: Department of Economics, 3151 Social Science Plaza, University of California, Irvine, CA 92697-5100. E-mail: fmilani@uci.edu. Homepage: http://www.socsci.uci.edu/ ${ }^{\text {fmilani. }}$ 

laugh.

"I know there's the myth of the autonomous Fed. . ." Nixon barked a quick laugh.

Richard Nixon, talking to Arthur Burns on October 23, 1969, just after Burns' nomination to the Fed had been announced. ${ }^{1}$

"I'd like to see another lowering of interest rates. I think there's room to do that. I can understand people worrying about inflation. But I don't think that's the big problem now".

24,1992 .

\section{Introduction}

Economic conditions before elections affect election outcomes. ${ }^{2}$ Rational politicians who recognize this regularity may, therefore, be tempted to try to influence the economy in the quarters preceding an election date to maximize their chances of being reelected.

The literature on Political Business Cycles (PBC) has developed models that rationalize economic fluctuations induced by political cycles. Nordhaus (1975) presented a model of "opportunistic" political cycles: the party in power stimulates the economy before elections to improve its reelection probability. Others have realistically argued that different parties may have different preferences over inflation and output or unemployment outcomes and, therefore, we should observe "partisan" political cycles. Hibbs (1977) was the first to introduce the partisan cycle model, in which left-wing parties were assumed to have at least one of the following: a higher output target, a higher inflation target, or a higher relative weight on minimizing output rather than inflation deviations from the targets, compared with right-wing parties. Alesina $(1987,1988)$ later extended Hibbs' model to introduce rational expectations.

Several papers test for the existence of opportunistic or partisan cycles in the US. Alesina, Cohen, and Roubini (1992) and Alesina, Roubini, and Cohen (1997) find only weak evidence of an opportunistic political cycle looking at M1 growth rates. Grier (1989) and Beck (1987), instead, find support for the effect of political variables on M1 growth rates for the 19601980 period, but not on the mean level of the federal funds rate. There is basically no evidence, instead, that political cycles matter for macroeconomic outcomes by looking at data on unemployment and output growth, and only weak evidence for inflation.

\footnotetext{
${ }^{1}$ Abrams (2006).

${ }^{2}$ Kramer (1971), Tufte (1975, 1978), Abrams (1980), Abrams and Butkiewitz (1995), Blomberg and Hess (2003), Fair (1978), and Alesina, Londregan, and Rosenthal (1993) provide evidence that favorable economic condition in the quarters prior a presidential election enhance the probability of the incumbent's being reelected.
} 
Empirical tests of the partisan cycle model (Alesina, Roubini, and Cohen 1997, Faust and Irons 1999) find partisan differences in output growth rates, but no support for partisan cycles in inflation and monetary policy.

Tests of PBC cycles typically assume monetary policy as the main tool that is exploited by politicians to manipulate the economy. These studies usually focus on comparing the level of inflation, output, money growth rates or interest rates across political cycles or they add a political dummy variable to the relevant regression and test its significance.

This paper takes a different approach. The paper aims to empirically test various political business cycle theories adopting an optimizing New Keynesian model with a monetary and fiscal policy mix as the main setting. The New Keynesian model is a baseline setting that is widely used in the analysis of monetary policy. The inclusion of both fiscal and monetary policy is motivated by Drazen $(2000 \mathrm{~b}) .^{3}$

The monetary and fiscal policy rule parameters, as well as parameters that reflect the frequency of price adjustment by firms and the steady-state level of inflation, are allowed to depend on the (observed) political regime.

Several hypotheses may thus be tested. The coefficients may, in fact, differ in pre-election versus no-election periods, they may depend on the Party affiliation of either the President or the Federal Reserve Chairman, and on whether the President and the Fed Chairman share the same affiliation or not in a pre-election period (the different cases are introduced one at a time in the model to save degrees of freedom).

Political cycles in monetary and fiscal policy are tested by looking at the various policy feedback coefficients rather than at the mean levels of outcome variables or money growth rates as typically done in the literature. The paper is, therefore, more closely related to the recent study by Abrams and Iossifov (2006), who use a Taylor rule during the 1957-2004 sample to test political cycle theories. They use, however, a single equation approach, while this paper employs a full-information Bayesian approach to estimate a general equilibrium model with both monetary and fiscal policy. The paper is also related to Faust and Irons (1999), who estimate an identified VAR in which the coefficients are contingent on the regime. The current paper, instead, uses a structural model to judge the importance of political

\footnotetext{
${ }^{3}$ Drazen (2000b) reviews the evidence accumulated in 25 years of political business cycle research and concludes that models based on monetary policy are not entirely convincing; he argues that a larger focus on fiscal policy, often disregarded in the literature, may prove more promising. There is evidence, in fact, that fiscal transfers are manipulated to gain an electoral advantage (Tufte 1978, Keech and Pak 1989, and Alesina 1988). Moreover, the use of monetary policy as the main driving force may be problematic. Politicians typically do not have full control of monetary policy, since this task is left to independent central banks.
} 
regimes. The structural model is considerably more parsimonious than Faust and Irons' VAR and allows for an easier interpretation of the coefficients.

If political cycles were important, agents should be able to incorporate this information into their expectations. Under the conventional assumption of rational expectations, however, agents would be assumed to know that political cycles exist and to have known this for the whole sample period. Besides, they would also have perfect knowledge about the 'size' of the political cycle effect and, under partisan cycles, about the different political parties' objective functions.

These are, of course, strong informational assumptions. Here I relax rational expectations, by assuming that economic subjects have to learn about economic relationships over time. Economic agents form near-rational expectations. They use a model of the economy that resembles the 'Minimum State Variable' solution under rational expectations, but they do not know the model parameters. Therefore, they use historical data to learn the relevant model coefficients over time. They use their perceived model and the updated parameter estimates to form expectations of future macroeconomic conditions, which they need to solve their optimal consumption and price-setting decisions. Agents in the model, therefore, are assumed to have the same knowledge an econometrician would have in real-time, in the spirit of the adaptive learning literature (e.g. Evans and Honkapohja 2001 for an overview). In this specification, the agents are allowed to learn from past observations how political business cycles affect fluctuations in output, inflation, and future policies. From a more empirical point of view, learning introduces time variation in the model, which helps fitting macroeconomic data, again in a very parsimonious way. ${ }^{4}$

The model is estimated using likelihood-based Bayesian methods on post-war U.S. data. The estimation approach follows Milani (2007), who shows how to estimate a Dynamic Stochastic General Equilibrium (DSGE) model with near-rational expectations and learning. The Bayesian approach facilitates the joint estimation of the learning parameters together with the 'deep' parameters of the economy and the policy feedback parameters. In this way, the learning process is jointly extrapolated from the data, rather than imposed a priori and the analysis conditioned on it. The relevance of different political business cycles' theories can then be gauged by looking at how the parameters' posterior distributions vary across regimes and by comparing the marginal likelihoods of the alternative model specifications.

\footnotetext{
${ }^{4}$ By changing only one parameter, the constant gain coefficient, very different learning processes may be obtained.
} 
Results. The results are supportive of the notion that political variables matter. Several policy parameters, as well as some of the economy's structural parameters, vary across political regimes. The best-fitting specification is one in which the relevant political regime is defined by whether the economy is in the few quarters preceding a Presidential election or not.

The results show that monetary policy becomes extremely inertial before the election. The rarity of policy changes is consistent with an independent Fed, which is also concerned about giving an impression of not actively participating in the political race. Apart from the inertia, there is some evidence, although not strong, that both monetary policy (before 1979) and fiscal policy become more expansionary before elections.

This paper mainly aims to add to the empirical literature on PBCs. But the paper can also be seen as a contribution to empirical studies of the New Keynesian model, aimed at testing whether the exclusion of political variables may have represented an important misspecification of the model. The paper is finally related to the literature that studies the monetary-fiscal policy mix (e.g. Favero and Monacelli 2005, Muscatelli, Tirelli, and Trecroci 2004) and to empirical applications of models with adaptive learning (e.g. Adam 2005, Milani 2007, Orphanides and Williams 2005).

\section{The Model}

I assume that the aggregate dynamics of the economy can be summarized by the following New Keynesian model, which is widely used to study monetary policy issues and which can be derived from the optimizing decisions of economic agents (see Woodford 2003 for a standard derivation):

$$
\begin{aligned}
x_{t} & =\widehat{E}_{t} x_{t+1}-\sigma\left(i_{t}-\widehat{E}_{t} \pi_{t+1}-r_{t}^{N}\right) \\
\pi_{t}-\pi^{*}\left(S_{t}\right) & =\beta \widehat{E}_{t}\left(\pi_{t+1}-\pi^{*}\left(S_{t}\right)\right)+\kappa\left(S_{t}\right) x_{t}+u_{t} \\
i_{t} & =\rho_{M P}\left(S_{t}\right) i_{t-1}+\left(1-\rho_{M P}\left(S_{t}\right)\right)\left[r_{t}^{N}+\right. \\
& \left.+\pi^{*}\left(S_{t}\right)+\chi_{\pi}\left(S_{t}\right)\left(\pi_{t-1}-\pi^{*}\left(S_{t}\right)\right)+\chi_{x}\left(S_{t}\right) x_{t-1}\right]+\varepsilon_{t} \\
d_{t} & =\rho_{F P}\left(S_{t}\right) d_{t-1}+\left(1-\rho_{F P}\right)\left(S_{t}\right)\left[\tau_{0}\left(S_{t}\right)+\tau_{B}\left(S_{t}\right) B_{t-1}+\tau_{x}\left(S_{t}\right) x_{t-1}\right]+\eta_{t}
\end{aligned}
$$

where $x_{t}$ denotes the output gap (the deviation of real from potential GDP), $\pi_{t}$ denotes inflation, $i_{t}$ is the nominal interest rate, $d_{t}$ denotes the budget deficit, $B_{t}=\beta^{-1}\left(B_{t-1}-\right.$ 
$\left.\pi_{t-1}+(1-\beta) d_{t-1}\right)+i_{t-1}$ is the debt to GDP ratio, $r_{t}^{N}$ denotes the natural rate of interest, ${ }^{5}$ $u_{t}$ is a cost-push supply shock, and $\varepsilon_{t}$ and $\eta_{t}$ are monetary and fiscal policy shocks. $r_{t}^{N}$ and $u_{t}$ are assumed to follow $\operatorname{AR}(1)$ processes $r_{t}^{N}=\rho_{r} r_{t-1}^{N}+\sigma_{r}\left(S_{t}\right) \nu_{t}^{r}$ and $u_{t}=\rho_{u} u_{t-1}+\sigma_{u}\left(S_{t}\right) \nu_{t}^{u}$, while $\varepsilon_{t}$ and $\eta_{t}$ are i.i.d. with mean 0 and variances $\sigma_{\varepsilon}\left(S_{t}\right)$ and $\sigma_{\eta}\left(S_{t}\right)$. S $S_{t}$ denotes the 'political' regime, which will be defined in more detail in section 2.2.

Equation (1) represents the log-linearized intertemporal Euler equation that derives from the households' optimal choice of consumption. The output gap depends on the expected oneperiod ahead output gap and on the ex-ante real interest rate. The coefficient $\sigma>0$ represents the intertemporal elasticity of substitution of consumption. Equation (2) is the forwardlooking New Keynesian Phillips curve that can be derived from the optimizing behavior of monopolistically-competitive firms under Calvo price setting (assuming, instead, quadratic adjustment costs in nominal prices would lead to the same law of motion). Inflation depends on expected inflation in $t+1$ and on current output gap. The parameter $0<\beta<1$ represents the households' discount factor, $\pi^{*}$ denotes the steady-state level of inflation, which is also the inflation target adopted by the central bank, and $\kappa$ denotes the slope of the Phillips curve. Equation (3) describes monetary policy. The central bank follows a Taylor rule by adjusting its policy instrument, a short-term nominal interest rate, in response to deviations of inflation and output gap from their targets (equal to $\pi^{*}$ for inflation and 0 for the output gap). $\chi_{\pi}$ and $\chi_{x}$ are the policy feedback coefficients and $\rho_{M P}$ accounts for interest-rate inertia.

This setting incorporates two extensions of the baseline 3-equations New Keynesian model. First, the model includes a fiscal policy rule, along with the usual Taylor rule that describes monetary policy. ${ }^{6}$ A fiscal policy rule is included in light of Drazen (2000b)'s argument that fiscal policy may be more relevant than monetary policy in revealing the effects of politics on macroeconomic decisions. The fiscal policy rule (4) implies a reaction of the budget deficit to the output gap and to current debt (debt to GDP ratio); $\tau_{x}$ and $\tau_{B}$ are the feedback coefficients (Taylor 2000 and Favero and Monacelli 2005 analyze similar rules and show that they can accurately describe the behavior of post-war U.S. fiscal policy). ${ }^{7}$

Second, the paper relaxes the strong informational assumption that requires agents to

\footnotetext{
${ }^{5}$ In this model $r_{t}^{N}$ is typically affected by changes in potential output as well as shocks to government spending. Fiscal policy, therefore, affects demand in the model only through changes in $r_{t}^{N}$.

${ }^{6}$ Typical studies of monetary policy in a New Keynesian framework often ignore fiscal policy, by assuming that the fiscal authority operates to maintain a zero-balance budget at all times. The details of fiscal policy usually do not affect the dynamics of the economy in such a model and are, therefore, ignored. Here, fiscal policy is, instead, included to test its dependence on political variables.

${ }^{7}$ The reaction to the output gap aims to account for the cyclical components of fiscal policy and can contain the effect due to the operation of automatic stabilizers.
} 
form fully-rational expectations. I assume what is usually considered as a 'small' deviation from rationality: agents use the endogenous variables that appear in the model's solution under rational expectations in their perceived model of the economy. But they are assumed to lack knowledge about the structural parameters. ${ }^{8}$ Therefore, they use historical data to estimate the model and learn the values of the relevant parameters over time. $\widehat{E}_{t}$, therefore, indicates subjective (near-rational) expectations and may differ from $E_{t}$ the usual expectation operator.

In the model, several coefficients are assumed to depend on the political regime. ${ }^{9}$ First, to test for the existence of political business cycles induced by policy, the monetary and fiscal policy coefficients are allowed to differ across political regimes. This differs from many previous PBC studies, which test the existence of cycles by comparing mean inflation, output, or money growth rates across regimes. Here, instead, I test whether the feedback coefficients to inflation and output, and, consequently, the relative importance of the two objectives, depend on political variables. Besides, I also allow the steady states of inflation and of the budget balance, which can be interpreted as the target levels that policymakers try to achieve, to be regime-dependent.

If opportunistic cycles are important, we might expect to observe, for example, an attenuated monetary policy reaction to deviations of inflation from target, possibly along with a higher inflation target and a higher budget deficit, while if partisan cycles matter we would probably observe a higher reaction coefficient to output than to inflation under Democratic Presidents (and again higher inflation and budget deficit targets). If, instead, the Fed is not politically-motivated, but, as some observers argue, simply wants to avoid taking any action as elections approach, the policy rule would still be characterized by lower reaction coefficients in pre-election quarters and maybe by more inertia.

The "deep" parameters of the economy should not, in principle, vary across regimes: $\beta$ is typically fixed in the literature and $\sigma$ will be estimated at a common value across regimes. It may be argued that $\kappa$, instead, which represents the slope of the Phillips curve and which is a negative function of the Calvo pricing parameter (the probability of resetting a price in any given period) may not be really interpreted as 'structural'. The likelihood of firms'

\footnotetext{
${ }^{8}$ As explained for example in Preston (2005) and Milani (2006), although they may be assumed to know their own preference parameters, they cannot infer the aggregate law of motions because they neither know other agents' preferences nor the value of aggregate parameters, such as Calvo's price stickiness coefficient.

${ }^{9}$ Here the regimes are assumed to be observed; therefore, the estimation of the model basically reduces to an estimation with an added dummy variable $\left(S_{t}\right)$. Faust and Irons (1999) assume a similar regime-contingent structure in their VAR model.
} 
changing prices, in fact, may depend on the specific policy environment and, in particular, on the prevailing inflation rate. Therefore, I let the data decide whether $\kappa$ varies across regimes or not. Finally, the different macroeconomic outcomes may be due to various degrees of luck rather than different policies: to account for this, the standard deviations of the supply and demand shocks, as well as the standard deviations of monetary and fiscal policy surprises are allowed to vary across regimes. ${ }^{10}$

By relaxing the standard assumptions that are usually imposed under rational expectations, economic agents are not endowed with the information that the parameters of the economy depend on political variables and they do not know their exact values. They are, however, allowed to learn from actual data the nature of economic relationships and the extent to which political regimes matter.

\subsection{Expectations Formation and Learning by Economic Agents}

As made clear by (1) and (2), economic agents need to form expectations of future macroeconomic variables. To form such expectations, I follow the adaptive learning literature (e.g. Evans and Honkapohja 2001) in assuming that they use a linear model of the economy, which represents their Perceived Law of Motion (PLM):

$$
Z_{t}=a_{t}+b_{t} Z_{t-1}+c_{t} B_{t-1}+d_{t} S_{t}+e_{t}
$$

where $Z_{t} \equiv\left[x_{t}, \pi_{t}, i_{t}, d_{t}\right]^{\prime} .{ }^{11}$ Agents do not know the relevant model parameters. They use historical data to learn those parameters over time. As additional data become available in subsequent periods, they update their estimates of the coefficients $\left(a_{t}, b_{t}, c_{t}, d_{t}\right)$ according to the constant-gain learning formula

$$
\begin{aligned}
\widehat{\phi}_{t} & =\widehat{\phi}_{t-1}+\overline{\mathbf{g}} R_{t}^{-1} X_{t}\left(Z_{t}-X_{t}^{\prime} \widehat{\phi}_{t-1}\right) \\
R_{t} & =R_{t-1}+\mathbf{g}\left(X_{t-1} X_{t-1}^{\prime}-R_{t-1}\right)
\end{aligned}
$$

where (6) describes the updating of the learning rule coefficients $\widehat{\phi}_{t}=\left(a_{t}^{\prime}, v e c\left(b_{t}, c_{t}, d_{t}\right)^{\prime}\right)^{\prime}$, and (7) describes the updating of the precision matrix $R_{t}$ of the stacked regressors $X_{t} \equiv$

\footnotetext{
${ }^{10}$ For monetary and fiscal policy disturbances, different standard deviations across regimes would also signal that deviations from the rules, i.e. unsystematic policy or policy surprises, are more common under one particular regime.

${ }^{11}$ The PLM includes the lagged values of the endogenous variables as does the Minimum State Variable solution of the system under rational expectations. Agents are, therefore, estimating a VAR(1) in the endogenous variables and they are assumed not to be able to observe the current value of the shocks $r_{t}^{N}$ and $u_{t}$, which would also appear in the RE solution. Not including the shocks in the VAR does not significantly affect the results and it appears as a more realistic description of the information set of economic agents.
} 
$\left\{1, x_{t-1}, \pi_{t-1}, i_{t-1}, d_{t-1}, B_{t-1}, S_{t}\right\}_{0}^{t-1}$. Therefore, agents' beliefs in $\widehat{\phi}_{t}$ are equal to their previous period values plus an update that is based on period-t's forecast error. $\bar{g}$ denotes the constant gain coefficient, ${ }^{12}$ which captures how quickly agents revise their beliefs due to incoming information.

\subsection{Political Regimes}

The different regimes I consider are:

1. a pre-election versus post-election regime. Here $S_{t}$ equals 1 in the 7 quarters before an election and 0 otherwise. Allowing the model parameters to depend on the regime allows me to test the role of opportunistic cycles in both monetary and fiscal policy.

2. Republican versus Democratic President. $S_{t}$ equals 1 if the President is a Democrat and 0 if Republican. I can, therefore, estimate the importance of partisan cycles in monetary and fiscal policy. ${ }^{13}$

3. Republican versus Democratic Federal Reserve Chairman: $S_{t}$ equals 1 if the Chairman is a Democrat and 0 if Republican. ${ }^{14}$ This division may be more relevant than (2) to test for the existence of partisan cycles in monetary policy.

4. A pre-election regime when the President and the Fed Chairman share party affiliation versus a different party or post-election regime. $S_{t}$ equals 1 when the President and the Chairman are both Democrats or both Republicans and we are in the 7 quarters preceding a presidential election. These regimes may provide a better test of the opportunistic cycles hypothesis, particularly in monetary policy. ${ }^{15}$

Using (5) and the updated estimates in (6), economic agents can form expectations as

$$
\widehat{E}_{t-1} Z_{t+1}=a_{t-1}\left(I+b_{t-1}\right)+b_{t-1}^{2} Z_{t-1}+\left(I+b_{t-1}\right) c_{t-1} B_{t-1}+d_{t-1} \widehat{E}_{t-1} S_{t+1},
$$

\footnotetext{
${ }^{12}$ Constant-gain learning has been used in Sargent (1999), Orphanides and Williams (2005), Primiceri (2006), and Milani (2007) among others.

${ }^{13}$ Fiscal policy may also depend on the Congress majority, not simply on the President. I leave the test of the effects of Congress to future work.

${ }^{14}$ The partisanship of a Chairman is measured by looking at the Party of the President who first nominated him. Greenspan, for example, who was first nominated by a Republican President and then renominated by Clinton, a Democrat, is counted as Republican for the whole term. Whether other FOMC members are Republicans or Democrats may also matter, but this complication is not considered here under the assumption that the Chairman plays a dominant role in decisions and that occasions in which the Chairman is put in minority during FOMC votes are extremely rare (this is documented in Chappell et al. 2005).

${ }^{15}$ Abrams and Iossifov (2006) find that this is the only political cycle hypothesis that is significant in their Taylor rules regressions.
} 
where $I$ denotes the identity matrix. I assume that economic agents can observe only macroeconomic variables up to $t-1$ when forming their expectations for $t+1$. In forming expectations about future output and inflation, they also need to forecast the future regime $\left(\widehat{E}_{t-1} S_{t+1}\right)$. When the regime is only a pre-election or post-election regime this is always trivial, since election dates are known in advance and, therefore $\widehat{E}_{t-1} S_{t+1}=S_{t+1}$. When the regimes, instead, depend on the winning party, the agents are assumed to forecast $S_{t+1}$ in the following way:

$$
\begin{cases}\widehat{E}_{t-1} S_{t+1}=S_{t+1} & \text { if } \quad q_{t} \neq 0 \\ \widehat{E}_{t-1} S_{t+1}=\Phi\left(S_{t}, x_{t-1}, x_{t-2}, x_{t-3}, x_{t-4}\right) & \text { if } \quad q_{t}=0\end{cases}
$$

where $q_{t} \in\{0, \ldots, 15\}$ denotes the number of quarters that have passed since the Presidential election date (a similar structure was assumed in Faust and Irons 1999). Therefore, when there is no upcoming election, $S_{t+1}$ is perfectly known. Every 16 quarters, however, economic subjects need to forecast the outcome of elections. They do it using estimates from a Probit model with past output gaps as regressors. ${ }^{16}$ In this way, they can forecast the probability that the incumbent will win the elections given the past relation between election outcomes and macroeconomic conditions.

Therefore, the formation of expectations, as characterized in (8), may differ according to the political cycle. Agents may learn from experience whether political variables matter or not.

\section{Bayesian Estimation}

I estimate the model by likelihood-based Bayesian methods. ${ }^{17}$ The Bayesian approach facilitates the estimation of the learning parameters jointly with the structural parameters of the economy. In particular, here I estimate the constant gain coefficient jointly with the parameters describing preferences and the monetary and fiscal policy rule parameters. ${ }^{18}$

\footnotetext{
${ }^{16}$ They are able to forecast the correct winner in 7 out of the 9 elections in the sample. It may be more realistic to allow agents to learn also about the Probit coefficients. Because of the small number of elections in the sample, however, I assume that they know the values of the full-sample Probit estimates, rather than letting them update the estimates over time. Notice that agents need only to forecast future election winners; they are assumed, instead, to be able to perfectly predict the party affiliation of the future Fed Chairman, since this has always coincided in the sample with the affiliation of the President who has to decide the first nomination.

${ }^{17}$ See An and Schorfheide (2007) for a review of the Bayesian estimation of DSGE models under rational expectations.

${ }^{18}$ The estimation strategy follows Milani (2007). Estimating also the constant gain coefficient is crucial, since the results are sometimes dependent on the chosen gain. For instance, Milani (2004) shows how the estimates of the backward-looking term in inflation vary over the possible gain values.
} 
Milani (2007) shows that learning improves the empirical fit of a similar New Keynesian model compared with the rational expectations case and it allows researchers to avoid including some of the so-called "mechanical" sources of persistence that are needed to make the model match the sluggishness of macroeconomic variables.

I use quarterly U.S. data on inflation, output gap, the federal funds rate, the budget balance, and the debt to GDP ratio. Inflation is calculated as the log change in the GDP Implicit Price Deflator converted at annual rates, and the output gap as the log deviation of Real GDP from Potential GDP (using the series computed by the Congressional Budget Office). The federal funds rate represents the monetary policy instrument, while the fiscal policy instrument is assumed to be the budget deficit, which is computed as Federal government current expenditures minus interest payments and minus Federal government current receipts as a fraction of GDP. $B_{t}$ in the model is given by the debt to GDP ratio. The data are shown in Figure 1. ${ }^{19}$

The model coefficients are collected in the vector $\theta$ :

$$
\theta\left(S_{t}\right)=\left\{\sigma, \pi^{*}\left(S_{t}\right), \kappa\left(S_{t}\right), \rho_{M P}\left(S_{t}\right), \chi_{\pi}\left(S_{t}\right), \chi_{x}\left(S_{t}\right), \rho_{F P}\left(S_{t}\right), \tau_{0}\left(S_{t}\right), \tau_{B}\left(S_{t}\right), \tau_{x}\left(S_{t}\right), Q\left(S_{t}\right), \overline{\mathbf{g}}\right\}
$$

where $Q\left(S_{t}\right)$ groups the regime-dependent standard deviations of the supply, demand, and policy shocks. The parameters depend on the political regime:

$$
\theta\left(S_{t}\right)=\theta_{0}\left(1-S_{t}\right)+\theta_{1}\left(S_{t}\right)
$$

where $S_{t}$ corresponds to one of the regimes discussed in the previous section.

The learning process in expressions (6) and (7) needs to be initialized. The initial beliefs $\widehat{\phi}_{0}$ and $R_{0}$ are derived from estimating the PLM (eq. 5) on pre-sample data (using observations from 1954:III to 1965:IV).

The model is then estimated using data from 1966:I to 2006:IV. ${ }^{20}$ The likelihood is computed for the four endogenous variables: inflation, output gap, federal funds rate, and budget deficit.

I use the Metropolis-Hastings algorithm to generate draws from the posterior distribution. At each iteration, the likelihood is evaluated using the Kalman filter. I consider 300,000 draws,

\footnotetext{
${ }^{19}$ All data series were downloaded from FRED, the economic database of the Federal Reserve of St. Louis, and are demeaned prior to the estimation.

${ }^{20}$ Data on debt are available from this date. The choice of 1966 as starting date is, however, sensible since it is often argued that the federal funds rate may be realistically considered the main instrument of monetary policy starting from around this date.
} 
discarding an initial burn-in of 75,000 draws. ${ }^{21}$

Table 1 describes the priors. I fix $\beta$ equal to $0.99 .{ }^{22}$ I assume a Gamma distribution with mean 1 for $\sigma$. The slope coefficient of the Phillips curve, $\kappa$, follows a Normal distribution with mean .2 and standard deviation .1. The monetary policy rule coefficients also follow Normal distributions with mean 1.5 and standard deviation .25 for the inflation feedback coefficients, and mean .5 and standard deviation .25 for the output feedback coefficients. I choose inverse gamma distributions for the standard deviations of the shocks and Beta distributions for the autoregressive coefficients. Finally, the constant gain coefficient follows a Gamma distribution with prior mean .031 and prior standard deviation .022.

I will emphasize in describing the results the cases in which the likelihood seems flat for some of the parameters and those for which the priors appear to have a strong influence on the shape of the posterior. ${ }^{23}$

\section{Results}

\subsection{Opportunistic Cycles in Fiscal and Monetary Policies}

I start by testing for the existence of opportunistic cycles. These can manifest themselves as an overstimulation of the economy during the quarters preceding an election. Monetary policymakers, for example, may be overly accommodative or they may simply attenuate their usual responses to output and inflation, by delaying any decisions until after the election.

Table 2 reports the estimation results, while Figure 2 compares the posterior distributions for the estimated parameters across regimes.

The monetary policy coefficients seem to depend on the political regime. During preelection quarters, the posterior distribution of the interest-rate smoothing coefficient $\rho_{M P}$ clearly shifts to the right (the estimated posterior mean switches from 0.877 to 0.97 ). This indicates that policy changes are rare before elections. The monetary policymaker prefers to keep rates fixed and to delay decisions until elections are over. This result supports the notion of an independent Fed that tries not to affect the political race and that wants to avoid being perceived as partisan. Some evidence, albeit moderate, of opportunistic cycles

\footnotetext{
${ }^{21}$ To monitor convergence, I perform a number of checks, which are described in the appendix.

${ }^{22}$ The parameter $\beta$ is pinned out by the steady-state relation $\beta=(1+r)^{-1}$, where $r$ is the steady-state real interest rate.

${ }^{23}$ Under the Bayesian approach, the potential non-identification of some of the parameters does not pose particular difficulties in the estimation (e.g. Poirier 1998). I will therefore estimate all the parameters and let the data speak about their identification.
} 
appears by looking at the other monetary policy coefficients: the reaction to inflation declines before elections (the posterior mean goes from 1.479 to 1.335), while the inflation target and the reaction to output become higher (the mean target increases from 2.54 to 3.16, the gap coefficient from 0.35 to 0.54 ).

Fiscal policy is likewise more inertial before elections (the posterior mean for $\rho_{F P}$ is 0.89 in pre-election quarters, 0.84 otherwise). The target deficit is also higher before elections, and the deficit becomes more responsive to the output gap (the deficit increases more when the output gap increases). The fiscal policy feedback coefficient to the output gap $\tau_{x}$ may contain two effects: mainly, the effect of automatic stabilizers, but also a component that reveals discretionary fiscal policy. Since the posterior distributions slightly differ across regimes, it might indicate that the discretionary component becomes slightly more important right before elections. ${ }^{24}$

The standard deviations of both monetary and fiscal policy surprises are strongly affected by the proximity of an election: fiscal policy deviations from the rule are considerably more common and sizeable before elections (the posterior distribution shifts to the right), while monetary policy deviations are less so (since, as seen, monetary policy decisions are unlikely in this regime).

Finally, another parameter that is crucially affected by the proximity to an election is $\kappa$, which denotes the slope of the Phillips curve and is an inverse function of the degree of price rigidity in the economy. The distribution of $\kappa$ tilts toward 0 when $S_{t}=1$, signaling that firms tend to have higher probability to keep prices fixed in the quarters before elections. From the estimated $\kappa$, we can derive the implied Calvo parameter $\alpha$, such that $(1-\alpha)$ denotes the probability of firms' changing prices in a given quarter (or equivalently, the fraction of firms that change prices in a given quarter). $(1-\alpha)$ goes from 0.28 in after-elections quarters to 0.17 right before elections. ${ }^{25}$ Therefore, firms prefer to delay the price-setting decision until the electoral uncertainty is resolved. ${ }^{26}$

\footnotetext{
${ }^{24}$ Taylor (2000) finds that the feedback to the output gap is mainly due to automatic stabilizers, while discretionary actions have been small and not consistent over time.

${ }^{25}$ In the presented model, $\kappa$ is a function of primitive parameters, $\kappa \equiv \frac{(1-\alpha)(1-\alpha \beta)}{\alpha} \frac{\left(\omega+\sigma^{-1}\right)}{1+\omega \theta}$, where $\alpha$ is the Calvo parameter, $\omega$ the elasticity of marginal costs to changes in income, $\sigma$ is the inverse of the intertemporal elasticity of substitution, and $\theta$ is the elasticity of substitution between differentiated goods. The calibration to calculate the implied $\alpha$ here assumes standard values: $\omega=0.8, \sigma=1$, and $\theta=7$.

${ }^{26}$ Garfinkel and Glazer (1994) looked at the distribution of wage contracts in election and non-election years and found that union and firms prefer to negotiate in the quarters immediately after the election rather than those immediately before. This paper's results similarly suggest that firms rationally choose to postpone their decision until after the election outcome is known.
} 


\subsection{Partisan Cycles in Fiscal and Monetary Policies}

Economic parameters and policies may systematically differ depending on whether a Republican or Democratic President is in the White House. Table 3 and Figure 3 provide evidence on this hypothesis. Again the monetary and fiscal policy parameters substantially differ across political regimes, although in a counterintuitive way. Monetary policy is more inertial during Republican terms; the feedback coefficient to inflation is higher and the feedback to the output gap lower under Democrats than under Republicans. ${ }^{27}$ This is the opposite of what is usually theorized by PBC studies. The posterior distributions of monetary policy parameters during Republican presidencies are also such that a nontrivial probability mass refers to policies that do not respect the Taylor principle. ${ }^{28}$ Fiscal policy also displays a higher target for the budget deficit and a lower reaction to changes in the output gap under Republican Presidents than under Democrats (fiscal policy with Democratic Presidents is considerably inertial, instead). ${ }^{29}$

Turning to other parameters, the demand and supply shocks that have hit the economy had higher standard deviation during Democratic terms.

\subsection{Partisan Cycles using Fed Chairman's Affiliation}

Since the Federal Reserve has full independence in setting monetary policy, the party's affiliation or sympathy of the Fed Chairman could be, in principle, more relevant than the President's party to test for partisan differences in monetary policy.

The estimation results, however, mirror those in the previous section. Fed Chairmen that were appointed by Democratic Presidents have on average reacted more aggressively toward inflation and cared less about output fluctuations compared with those appointed by Republican Presidents. It should be emphasized, however, that only few changes in the relevant political variable are available in the sample and, therefore, the results are likely to depend a lot on Arthur Burns' passive monetary policy (which is counted as Republican) and Paul Volcker's aggressive policy during the disinflation (which affects the results for Democrats).

\footnotetext{
${ }^{27}$ The data do not appear very informative, in this case, about the value of the inflation target: the posterior distributions are very close to the priors.

${ }^{28}$ The Taylor principle in this model is given by the following condition (Woodford 2003$): \chi_{\pi}+\left(\frac{1-\beta}{\kappa}\right) \chi_{x}>1$.

${ }^{29}$ The results could, of course, depend on the smaller variation in the regime variable when partisan cycles, rather than opportunistic cycles, are analyzed. Therefore, episodes such as Volcker's fight against inflation (during Carter's term) and Burns' accommodating monetary policy in the Nixon years can significantly affect the monetary policy results, as, in the same way, the budget surplus during Clinton's presidency along with the deficits during Bush and Reagan's presidencies may greatly influence the fiscal policy conclusions.
} 


\subsection{Opportunistic Cycles in Monetary Policy when the President and the Fed Chairman Share Party Affiliation}

It may be realistic to argue that opportunistic cycles are present only when the Fed Chairman shares political party with the President. Abrams and Iossifov (2006), in fact, find that this is the only case in which political cycles matter in their estimated Taylor rules. Along the same lines, Chappell, McGregor, and Vermilyea (2005), analyzing FOMC voting records, show that FOMC members are more likely to support a pre-election expansionary monetary policy when they were appointed by a president of the incumbent party.

The evidence, presented in Table 5 and Figure 5, is similar to that on opportunistic cycles. Monetary policy is especially inertial before elections even when the President and the Fed Chairman have similar political sympathies. There is evidence of a lower reaction toward inflation, a higher inflation target, and a larger reaction to changes in the output gap before elections.

\subsection{Beliefs}

Economic agents were allowed to update their beliefs over time. Figure 6 shows two selected parameters that appear to have considerably changed over the sample. One is the perceived sensitivity of the output gap to changes in the interest rate. Agents' beliefs evolve over the sample to reflect the perception of declining sensitivity. The second is the autoregressive coefficient in the perceived law of motion for inflation, which indicates changes in the perceived persistence of this variable. The estimated coefficient starts at values close to 0 , but it considerably increases from the late 1960s to the early 1970s and later in the 1980s, to decline again to low values at the end of the sample. Adding learning to the model admits this important time variation in beliefs, which would be ruled out under rational expectations.

Figure 7, instead, shows the evolving agents' beliefs about the importance of the different political variables. For example, looking at the first row in the graph, it can be seen that agents adjust their beliefs in the 1970s as they are learning that policy rates are lower and the budget deficit higher before elections. During Carter's term, though, these beliefs are quickly revised. In a way that is consistent with the model estimates, agents perceive more contractionary monetary and fiscal policies during Democratic terms. 


\subsection{Model Comparison}

The paper has reported estimates for several models and shown which political variables seem to matter for policy decisions and macroeconomic outcomes. But which of the models estimated so far provides the best fit of the data?

To evaluate the fit of the models, I compare their marginal likelihoods using Geweke's modified harmonic mean approximation (Table 6). ${ }^{30}$ The marginal likelihoods favor the opportunistic cycles model. The opportunistic cycle when the President and the Fed Chairman come from the same party ranks second. Of course partisan cycles may also be present - I simply find that, as a single explanation, they fit less well than opportunistic cycles - but the limited data do not allow including more than one regime at a time in the model. Partisan cycles may also suffer from a lower variability of the regime over the sample.

\subsection{What Would Have Monetary and Fiscal Policy Been in the Absence of Political Effects?}

Under opportunistic cycles, which is the case that is most supported by the data, the monetary and fiscal policy rules differ in pre- versus post-election quarters. But how large are the differences in practice?

Figure 8 displays the deviations in the monetary and fiscal policy instruments that are found by comparing the implied Federal Funds rate and budget deficit obtained by using the same policy rules that are estimated for non-election quarters for the whole sample, with those implied by rules that differ, as estimated, in pre-election quarters. The graph shows that monetary policy has typically been more expansionary before elections in the pre-1979 sample, but after Volcker, the increased inertia seems to have led the central bank to be, instead, more contractionary, except in the later part of the sample. Fiscal policy has been consistently more expansionary before elections, with the main exception being during Clinton years.

\subsection{Post-1985 Sample}

Tempelman (2007) has argued that the positive evidence of political cycles in US monetary policy found by Abrams and Yossifov (2006) may be due to their use of a long sample. The effect may not have been stable over such a sample and if tested only over the second

\footnotetext{
${ }^{30}$ The marginal likelihood as a measure of fit automatically penalizes models for an excessive number of parameters.
} 
half, there would be no evidence of political cycles. I test this argument by repeating the estimation on data starting from 1985:I.

Monetary policy is still considerably more inertial before elections, and so is fiscal policy (Figure 9). There is no evidence that monetary policy cares differently about inflation in the proximity of elections: the inflation target and inflation feedback coefficient are characterized by posterior distributions that substantially overlap. ${ }^{31}$ For monetary policy, however, some evidence exists that the reaction to the output gap is higher before elections. There isn't much evidence of an opportunistic cycle in fiscal policy: $\tau_{b}$ is now positive (and slightly larger near elections), but the target deficit is lower when $S_{t}=1 .{ }^{32}$

\section{Conclusions}

This paper has tested whether the coefficients of a baseline New Keynesian model depend on political variables. The paper has provided empirical evidence on PBC theories, testing different versions of both opportunistic and partisan cycle models.

The results provide support for the existence of changes in the economic structure and policies that are due to political variables. The best-fitting model is one which allows policy and structural parameters to depend on whether the economy is or not in pre-election quarters, as in opportunistic cycles' models. The results, however, are not entirely consistent with opportunistic cycles as they are usually interpreted.

The major difference in pre-election quarters is that monetary policy becomes considerably more inertial: the Fed seems to delay changes in policy until after the election. This is consistent with the view of an independent Fed, which does not want to be seen as an active player in the Presidential race. Some evidence, however, exists that both monetary and fiscal policies are more somewhat less concerned about inflation and more about output before elections.

As a future avenue for research, it may be worthwhile testing for electoral effects in fiscal policy at a lower level of aggregation. In this paper, the fiscal policy instrument has been considered to be the budget deficit. But future work may fruitfully test whether political variables matter more for government spending or for average tax rates, and, regarding spending, for which categories of government spending in particular. Likewise, future research

\footnotetext{
${ }^{31}$ The exact estimates somewhat depend on the exact starting date of the sample, but the main conclusions remain.

${ }^{32}$ Due to the small sample, this may be largely affected by Clinton surplus in the quarters before the 2000 election.
} 
should investigate whether the change in policies before elections displays asymmetries across recessions and expansions.

\section{References}

[1] Abrams, B.A. (1980), "The Influence of State-Level Economic Conditions on Presidential Elections," Public Choice, 35, pp. 623-631.

[2] Abrams, B.A. (2006), "How Richard Nixon Pressured Arthur Burns: Evidence From the Nixon Tapes", Journal of Economic Perspectives, Vol. 20, No. 4, 177-188.

[3] Abrams, B.A., and J.B. Butkiewitz (1995), "The Influence of State-Level Economic Conditions on the 1992 Presidential Election," Public Choice, 85, pp. 1-10.

[4] Abrams B.A., and P. Iossifov (2006), "Does the Fed Contribute to the Political Business Cycle?", Public Choice, Vol. 129, Iss.3, 249-262.

[5] Adam, K. (2005) "Learning to Forecast and Cyclical Behavior of Output and Inflation", Macroeconomic Dynamics, Vol. 9(1), 1-27.

[6] An, S., and F. Schorfheide, (2007). "Bayesian Analysis of DSGE Models", Econometric Reviews, Vol. 26, Issue 2-4, pages 113-172.

[7] Alesina, A. (1987), "Macroeconomic Policy in a Two-Party System as a Repeated Game," Quarterly Journal of Economics, 102, 651-78.

[8] Alesina, A. (1988), "Macroeconomics and Politics," NBER Macroeconomics Annual, Cambridge MA: MIT Press.

[9] Alesina, A., G. Cohen, and N. Roubini (1992), "Macroeconomic Policy and Elections in OECD Democracies", Economics and Politics 4, 1-30.

[10] Alesina, A., J. Londregan, and H. Rosenthal (1993), "A Model of the Political Economy of the United States," American Political Science Review 87(1):12-33.

[11] Alesina, A., N. Roubini and G. Cohen (1997), Political Cycles and the Macroeconomy, Cambridge MA: MIT Press.

[12] Beck, N. (1987), "Elections and the Fed: Is There a Political Monetary Cycle?," American Journal of Political Science 31, 194-216.

[13] Blomberg, B.S., and G.D. Hess (2003), "Is the Political Business Cycle for Real?", Journal of Public Economics, vol. 87(5-6), pages 1091-1121.

[14] Chappell, E.W., R.R. McGregor, and T. Vermilyea (2005), Committee Decisions on Monetary Policy: Evidence from Historical Records of the Federal Open Market Committee, MIT Press.

[15] Drazen, A. (2000a), Political Economy in Macroeconomics, Princeton, NJ: Princeton University Press.

[16] Drazen, A. (2000b), "The Political Business Cycle after 25 Years", NBER Macroeconomics Annual, 75-117.

[17] Evans, G.W., and S. Honkapohja, (2001). Learning and Expectations in Macroeconomics, Princeton University Press.

[18] Fair, R. (1978), "The Effect of Economic Events on Votes for President," Review of Economics and Statistics, Vol. 60, 159-72. 
[19] Fang, A., and I. Jeliazkov (2007), "Politics and Macroeconomic Performance in the United States: Cycles and Long-Run Outcomes", manuscript, University of California, Irvine.

[20] Faust, J. and J. Irons (1999), "Money, Politics, and the Post-War Business Cycle," Journal of Monetary Economics 43, 61-89.

[21] Favero, C.A., and T. Monacelli (2005), "Monetary-Fiscal Mix and Inflation Performance: Evidence from the U.S.", mimeo, IGIER - Bocconi University.

[22] Garfinkel, M. and A. Glazer (1994), "Does Electoral Uncertainty Cause Economic Fluctuations?," American Economic Review 84, 169-73.

[23] Grier, K.B. (1989), "On the Existence of a Political Monetary Cycle," American Journal of Political Science 33, 376-89.

[24] Hibbs, D. (1977), "Political Parties and Macroeconomic Policy," American Political Science Review 71, 1467-87.

[25] Hibbs, D. (1994), "The Partisan Model of Macroeconomic Cycles: More Theory and Evidence for the United States," Economics and Politics 6, 1-24.

[26] Keech, W. and K. Pak (1989), "Electoral Cycles and Budgetary Growth in Veterans Benefit Programs," American Journal of Political Science 33, 901-11.

[27] Kramer, G.H. (1971), "Short-Term Fluctuations in U.S. Voting Behavior, 1896-1964," The American Political Science Review 65, 131-143.

[28] Krause, S., and F. Mendez (2005), "Policy Makers' Preferences, Party Ideology and the Political Business Cycle", Southern Economic Journal, 71(4), pp. 752-767.

[29] Milani, F. (2004), "Adaptive Learning and Inflation Persistence", mimeo, University of California, Irvine.

[30] Milani, F. (2006), "A Bayesian DSGE Model with Infinite-Horizon Learning: Do "Mechanical" Sources of Persistence Become Superfluous?", International Journal of Central Banking, Issue 6, September 2006.

[31] Milani, F. (2007), "Expectations, Learning and Macroeconomic Persistence", Journal of Monetary Economics, Volume 54, Issue 7, 2065-2082.

[32] Muscatelli, A., P. Tirelli, and C. Trecroci (2003), "Fiscal and Monetary Policy Interactions: Empirical Evidence and Optimal Policy Using a Structural New-Keynesian Model," Journal of Macroeconomics, vol. 26(2), 257-280.

[33] Nordhaus, W. (1975), "The Political Business Cycle," Review of Economic Studies 42, 169-90.

[34] Orphanides, A., and J. Williams (2005), "The Decline of Activist Stabilization Policy: Natural Rate Misperceptions, Learning, and Expectations", Journal of Economic Dynamics and Control, vol. 29(11), pages 1927-1950.

[35] Poirier, D. (1998), Revising Beliefs in Nonidentified Models," Econometric Theory, 14(4), 483509 .

[36] Preston, B. (2005). "Learning About Monetary Policy Rules When Long-Horizon Expectations Matter", International Journal of Central Banking, Issue 2, September.

[37] Primiceri, G. (2006), "Why Inflation Rose and Fell: Policymakers' Beliefs and Postwar Stabilization Policy", Quarterly Journal of Economics, Vol. 121(3), 867-901. 
[38] Rogoff, K. (1990), "Equilibrium Political Budget Cycles," American Economic Review $80,21-36$.

[39] Sargent, T.J. (1999). The Conquest of American Inflation, Princeton University Press.

[40] Taylor, J.B. (2000), "Reassessing Discretionary Fiscal Policy," Journal of Economic Perspectives, Vol. 14, No. 3, pp. 21-36.

[41] Tempelman, J. (2007), A commentary on "Does the Fed Contribute to a Political Business Cycle?", Public Choice, vol. 132, issue 3, 433-436.

[42] Tufte, E. (1975), "Determinants of the Outcomes of Midterm Congressional Elections," American Political Science Review 69, 812-26.

[43] Tufte, E. (1978), Political Control of the Economy, Princeton NJ: Princeton University Press.

[44] Walsh, C. (2000), "The Political Business Cycle after 25 Years: Comment", NBER Macroeconomics Annual, Vol. 15, pp. 124-135.

[45] Woodford, M. (2003). Interest and Prices: Foundations of a Theory of Monetary Policy, Princeton University Press.

[46] Woolley, John T. (1984), Monetary Politics: The Federal Reserve and the Politics of Monetary Policy, Cambridge, UK: Cambridge University Press. 


\section{A Metropolis-Hastings Algorithm}

The information about the parameters is summarized by the posterior distribution, obtained by Bayes Theorem

$$
p\left(\theta \mid Y^{T}\right)=\frac{p\left(Y^{T} \mid \theta\right) p(\theta)}{p\left(Y^{T}\right)}
$$

where $p\left(Y^{T} \mid \theta\right)$ is the likelihood function, $p(\theta)$ the prior for the parameters, and $Y^{T}=$ $\left[y_{1}, \ldots, y_{T}\right]^{\prime}$ collects the data histories.

To generate draws from the posterior distribution $p\left(\theta \mid Y^{T}\right)$, I use the Metropolis algorithm. The procedure works as follows.

1. Start from an arbitrary value for the parameter vector $\theta_{0}$. Set $j=1$.

2. Evaluate $p\left(Y^{T} \mid \theta_{0}\right) p\left(\theta_{0}\right)$

3. Generate $\theta_{j}^{*}=\theta_{j-1}+\varepsilon$, where $\theta_{j}^{*}$ is the proposal draw and $\varepsilon \sim N\left(0, c \Sigma_{\varepsilon}\right)$. $c$ is a scale factor that is usually adjusted to keep the acceptance ratio of the $\mathrm{MH}$ algorithm at an optimal rate (25\%-50\%, see Geweke 1999). The acceptance rates in the estimation are all between 35 and $40 \%$.

4. Generate $u$ from a Uniform $[0,1]$

5. Set $\left\{\begin{array}{l}\theta_{j}=\theta_{j}^{*} \quad \text { if } u \leq \alpha\left(\theta_{j-1}, \theta_{j}^{*}\right)=\min \left\{\frac{p\left(Y^{T} \mid \theta_{j}^{*}\right) p\left(\theta_{j}^{*}\right)}{p\left(Y^{T} \mid \theta_{j-1}\right) p\left(\theta_{j-1}\right)}, 1\right\} \\ \theta_{j}=\theta_{j-1} \quad \text { if } u>\alpha\left(\theta_{j-1}, \theta_{j}^{*}\right)\end{array}\right.$

6. Repeat for $j+1$ from 2. until $j=D$ ( $D=$ total number of draws).

\section{A.1 Convergence}

To assess convergence of the MCMC (Markov Chain Monte Carlo) simulation, I performed various checks, besides looking at the trace plots of the draws. I have considered the convergence tests proposed by Geweke (1992), and Raftery and Lewis (1995). Raftery and Lewis (1995)'s diagnostics suggests a minimum number of total draws, a thinning parameter, and a minimum burn-in, by computing the autocorrelation of the draws. Geweke's test instead compares the partial means $\widehat{\mu}_{1}=\frac{1}{D_{1}} \sum_{j=1}^{D_{1}} g\left(\theta_{j}\right)$ and $\widehat{\mu}_{2}=\frac{1}{D_{2}} \sum_{j=D_{1}+1}^{D_{2}} g\left(\theta_{j}\right)$, obtained from the first $D_{1}$ and last $D_{2}$ simulation draws. The null hypothesis of equal means between the two samples of draws can be tested knowing that, for $D \rightarrow \infty$, the quantity $\left(\widehat{\mu}_{1}-\widehat{\mu}_{2}\right) /\left(\frac{\widehat{S}_{g}^{1}(0)}{D_{1}}+\frac{\widehat{S}_{g}^{2}(0)}{D_{2}}\right)^{1 / 2} \Longrightarrow N(0,1)$. I also look at the plots derived from the test proposed by $\mathrm{Yu}$ and Mykland (1994), based on CUMSUM plots of the draws. ${ }^{33}$ Finally, I ascertain convergence by looking at the recursive mean plots and bivariate scatter plots among the parameters to evaluate the mixing of the chain.

\footnotetext{
${ }^{33}$ They propose the statistics $C S_{t}=\left(\frac{1}{t} \sum_{d=1}^{t} \theta^{d}-\mu_{\theta}\right) / \sigma_{\theta}$, where $\mu_{\theta}$ and $\sigma_{\theta}$ are the empirical mean and standard deviations of the $D$ draws of the Markov Chain. The plot of $C S_{t}$ converges to 0 as $t$ increases.
} 


\begin{tabular}{|l|c|l|l|c|c|}
\hline \hline & & \multicolumn{3}{|c|}{ Prior Distribution } \\
\hline Description & Parameter & Distr. & Support & Prior Mean & $95 \%$ Prior Prob. Interval \\
\hline Inverse IES & $\sigma^{-1}$ & $\Gamma$ & $\mathbb{R}^{+}$ & 1 & {$[0.12-2.78]$} \\
Discount Factor & $\beta$ & - & - & 0.99 & - \\
Slope Phillips Curve & $\kappa\left(S_{t}\right)$ & $\Gamma$ & $\mathbb{R}^{+}$ & 0.25 & {$[0.03-0.69]$} \\
Inflation Target & $\pi^{*}\left(S_{t}\right)$ & $N$ & $\mathbb{R}$ & 3 & {$[1.04-4.96]$} \\
MP Inertia & $\rho_{M P}\left(S_{t}\right)$ & $B$ & {$[0,1]$} & 0.8 & {$[0.459-0.985]$} \\
MP Inflation feedback & $\chi_{\pi}\left(S_{t}\right)$ & $N$ & $\mathbb{R}$ & 1.5 & {$[1.01-1.99]$} \\
MP Output Gap feedback & $\chi_{x}\left(S_{t}\right)$ & $N$ & $\mathbb{R}$ & 0.5 & {$[0.01-0.99]$} \\
FP Inertia & $\rho_{F}\left(S_{t}\right)$ & $B$ & {$[0,1]$} & 0.8 & {$[0.459-0.985]$} \\
Budget Deficit Target & $\tau_{0}\left(S_{t}\right)$ & $N$ & $\mathbb{R}$ & 0 & {$[-2.66-1.26]$} \\
FP Debt feedback & $\tau_{B}\left(S_{t}\right)$ & $N$ & $\mathbb{R}$ & 0 & {$[-0.49-0.49]$} \\
FP Output Gap feedback & $\tau_{x}\left(S_{t}\right)$ & $N$ & $\mathbb{R}$ & -0.5 & {$[-0.99 /-0.01]$} \\
Std. Demand Shock & $\sigma_{r}\left(S_{t}\right)$ & $\Gamma-1$ & $\mathbb{R}^{+}$ & 1 & {$[0.34-2.76]$} \\
Std. Supply Shock & $\sigma_{u}\left(S_{t}\right)$ & $\Gamma-1$ & $\mathbb{R}^{+}$ & 1 & {$[0.34-2.76]$} \\
Std. MP Shock & $\sigma_{\varepsilon}\left(S_{t}\right)$ & $\Gamma-1$ & $\mathbb{R}^{+}$ & 1 & {$[0.34-2.76]$} \\
Std. FP Shock & $\sigma_{\eta}\left(S_{t}\right)$ & $\Gamma$ & $\mathbb{R}^{+}$ & 1 & {$[0.34-2.76]$} \\
Autoregr. coeff. $r_{t}^{N}$ & $\rho_{r}$ & $B$ & {$[0,1]$} & 0.8 & {$[0.459-0.985]$} \\
Autoregr. coeff. $u_{t}$ & $\rho_{u}$ & $B$ & {$[0,1]$} & 0.8 & {$[0.459-0.985]$} \\
Constant Gain & $\overline{\mathbf{g}}$ & $\Gamma$ & $\mathbb{R}^{+}$ & 0.031 & {$[0.003-0.087]$} \\
\hline \hline
\end{tabular}

Table 1 - Prior Distributions.

( $U=$ Uniform, $N=$ Normal, $\Gamma=$ Gamma, $B=$ Beta, $\Gamma^{-1}=$ Inverse Gamma) 


\begin{tabular}{|l|c|c|c|c|c|}
\hline \hline Pre vs. Post-ELECTION & & \multicolumn{3}{|c|}{ Posterior Distribution } \\
\hline & & \multicolumn{2}{|c|}{$S_{t}=0$} & \multicolumn{2}{c|}{$S_{t}=1$} \\
\hline Description & Parameter & Mean & $95 \%$ PPI & Mean & $95 \%$ PPI \\
\hline Inverse IES & $\sigma^{-1}$ & 8.33 & {$[5.88-11.47]$} & 8.33 & {$[5.88-11.47]$} \\
Discount Factor & $\beta$ & 0.99 & - & 0.99 & - \\
Slope PC & $\kappa\left(S_{t}\right)$ & 0.108 & {$[0.03-0.20]$} & 0.036 & {$[0.004-0.09]$} \\
Inflation Target & $\pi^{*}\left(S_{t}\right)$ & 2.54 & {$[0.62-4.42]$} & 3.16 & {$[1.21-5.16]$} \\
MP Inertia & $\rho_{M P}\left(S_{t}\right)$ & 0.877 & {$[0.80-0.94]$} & 0.97 & {$[0.93-0.995]$} \\
MP Inflation feedback & $\chi_{\pi}\left(S_{t}\right)$ & 1.479 & {$[1.06-1.92]$} & 1.335 & {$[0.84-1.82]$} \\
MP Output Gap feedback & $\chi_{x}\left(S_{t}\right)$ & 0.35 & {$[-0.09-0.85]$} & 0.54 & {$[0.05-1.03]$} \\
FP Inertia & $\rho_{F P}\left(S_{t}\right)$ & 0.84 & {$[0.74-0.93]$} & 0.89 & {$[0.79-0.97]$} \\
Budget Deficit Target & $\tau_{0}\left(S_{t}\right)$ & -0.74 & {$[-1.52-0.05]$} & -0.61 & {$[-1.48-0.33]$} \\
FP Debt feedback & $\tau_{B}\left(S_{t}\right)$ & -0.0016 & {$[-0.04-0.04]$} & -0.004 & {$[-0.044-0.038]$} \\
FP Output Gap feedback & $\tau_{x}\left(S_{t}\right)$ & -0.42 & {$[-0.7 /-0.17]$} & -0.52 & {$[-0.89 /-0.17]$} \\
Std. Demand Shock & $\sigma_{r}\left(S_{t}\right)$ & 0.62 & {$[0.54-0.63]$} & 0.56 & {$[0.47-0.66]$} \\
Std. Supply Shock & $\sigma_{u}\left(S_{t}\right)$ & 0.87 & {$[0.77-1.01]$} & 0.82 & {$[0.69-0.99]$} \\
Std. MP Shock & $\sigma_{\varepsilon}\left(S_{t}\right)$ & 1.07 & {$[0.93-1.24]$} & 0.88 & {$[0.75-1.05]$} \\
Std. FP Shock & $\sigma_{\eta}\left(S_{t}\right)$ & 0.58 & {$[0.5-0.67]$} & 0.70 & {$[0.59-0.83]$} \\
Autoregr. coeff. $r_{t}^{N}$ & $\rho_{r}$ & 0.81 & {$[0.72-0.91]$} & 0.81 & {$[0.72-0.91]$} \\
Autoregr. coeff. $u_{t}$ & $\rho_{u}$ & 0.47 & {$[0.33-0.71]$} & 0.47 & {$[0.33-0.71]$} \\
Constant Gain & $\overline{\mathrm{g}}$ & 0.058 & {$[0.055-0.061]$} & 0.058 & {$[0.055-0.061]$} \\
\hline \hline
\end{tabular}

Table 2 - Posterior Estimates: Pre-Election vs. Post-Election Regime $\left(S_{t}=1\right.$ if the economy is in the seven quarters before an election date, $S_{t}=0$ otherwise). The table displays the posterior mean estimates across regimes and the $95 \%$ posterior probability intervals. 


\begin{tabular}{|l|c|c|c|c|c|}
\hline \hline President's Party & & \multicolumn{3}{|c|}{ Posterior Distribution } \\
\hline & & \multicolumn{2}{|c|}{$S_{t}=0$} & \multicolumn{2}{c|}{$S_{t}=1$} \\
\hline Description & Parameter & Mean & $95 \%$ PPI & Mean & $95 \%$ PPI \\
\hline Inverse IES & $\sigma^{-1}$ & 7.65 & {$[5.42-10.64]$} & 7.65 & {$[5.42-10.64]$} \\
Discount Factor & $\beta$ & 0.99 & - & 0.99 & - \\
Slope PC & $\kappa\left(S_{t}\right)$ & 0.062 & {$[0.01-0.13]$} & 0.054 & {$[0.008-0.13]$} \\
Inflation Target & $\pi^{*}\left(S_{t}\right)$ & 2.98 & {$[1.04-4.87]$} & 3.01 & {$[1.01-4.93]$} \\
MP Inertia & $\rho_{M P}\left(S_{t}\right)$ & 0.906 & {$[0.85-0.96]$} & 0.837 & {$[0.69-0.95]$} \\
MP Inflation feedback & $\chi_{\pi}\left(S_{t}\right)$ & 1.11 & {$[0.65-1.60]$} & 1.37 & {$[0.96-1.84]$} \\
MP Output Gap feedback & $\chi_{x}\left(S_{t}\right)$ & 0.59 & {$[0.19-1.02]$} & 0.19 & {$[-0.19-0.73]$} \\
FP Inertia & $\rho_{F}\left(S_{t}\right)$ & 0.83 & {$[0.72-0.93]$} & 0.97 & {$[0.93-0.995]$} \\
Budget Deficit Target & $\tau_{0}\left(S_{t}\right)$ & -0.35 & {$[-1.27-0.56]$} & -0.72 & {$[-1.72-0.26]$} \\
FP Debt feedback & $\tau_{B}\left(S_{t}\right)$ & 0.014 & {$[-0.02-0.05]$} & 0.03 & {$[-0.01-0.07]$} \\
FP Output Gap feedback & $\tau_{x}\left(S_{t}\right)$ & -0.357 & {$[-0.68 /-0.07]$} & -0.50 & {$[-0.92 /-0.05]$} \\
Std. Demand Shock & $\sigma_{r}\left(S_{t}\right)$ & 0.65 & {$[0.57-0.74]$} & 0.89 & {$[0.73-1.07]$} \\
Std. Supply Shock & $\sigma_{u}\left(S_{t}\right)$ & 0.83 & {$[0.72-0.95]$} & 0.98 & {$[0.82-1.19]$} \\
Std. MP Shock & $\sigma_{\varepsilon}\left(S_{t}\right)$ & 0.96 & {$[0.84-1.11]$} & 1.02 & {$[0.85-1.23]$} \\
Std. FP Shock & $\sigma_{\eta}\left(S_{t}\right)$ & 0.73 & {$[0.64-0.84]$} & 0.40 & {$[0.34-0.49]$} \\
Autoregr. coeff. $r_{t}^{N}$ & $\rho_{r}$ & 0.865 & {$[0.79-0.94]$} & 0.865 & {$[0.79-0.94]$} \\
Autoregr. coeff. $u_{t}$ & $\rho_{u}$ & 0.22 & {$[0.11-0.35]$} & 0.22 & {$[0.11-0.35]$} \\
Constant Gain & $\bar{g}$ & 0.0508 & {$[0.048-0.053]$} & 0.0508 & {$[0.048-0.053]$} \\
\hline \hline
\end{tabular}

Table 3 - Posterior Estimates: Partisan Cycles, Republican vs. Democratic President $\left(S_{t}=1\right.$ if the President is a Democrat, $S_{t}=0$ if a Republican). The table displays the posterior mean estimates across regimes and the $95 \%$ posterior probability intervals. 


\begin{tabular}{|l|c|c|c|c|c|}
\hline \hline Fed Chairman's Party & & \multicolumn{4}{|c|}{ Posterior Distribution } \\
\hline & & \multicolumn{2}{|c|}{$S_{t}=0$} & \multicolumn{2}{|c|}{$S_{t}=1$} \\
\hline Description & Parameter & Mean & $95 \%$ PPI & Mean & $95 \%$ PPI \\
\hline Inverse IES & $\sigma^{-1}$ & 5.64 & {$[3.75-8.25]$} & 5.64 & {$[3.75-8.25]$} \\
Discount Factor & $\beta$ & 0.99 & - & 0.99 & - \\
Slope PC & $\kappa\left(S_{t}\right)$ & 0.062 & {$[0.01-0.15]$} & 0.069 & {$[0.01-0.17]$} \\
Inflation Target & $\pi^{*}\left(S_{t}\right)$ & 2.98 & {$[0.78-4.92]$} & 2.77 & {$[0.85-4.58]$} \\
MP Inertia & $\rho_{M P}\left(S_{t}\right)$ & 0.904 & {$[0.78-0.99]$} & 0.834 & {$[0.70-0.94]$} \\
MP Inflation feedback & $\chi_{\pi}\left(S_{t}\right)$ & 0.91 & {$[0.32-1.68]$} & 1.47 & {$[1.01-1.92]$} \\
MP Output Gap feedback & $\chi_{x}\left(S_{t}\right)$ & 0.71 & {$[0.24-1.13]$} & 0.12 & {$[-0.34-1.65]$} \\
FP Inertia & $\rho_{F P}$ & 0.90 & {$[0.83-0.96]$} & 0.90 & {$[0.83-0.96]$} \\
Budget Deficit Target & $\tau_{0}$ & -0.82 & {$[-1.78-0.15]$} & -0.82 & {$[-1.78-0.15]$} \\
FP Debt feedback & $\tau_{B}$ & 0.035 & {$[-0.005-0.074]$} & 0.035 & {$[-0.005-0.074]$} \\
FP Output Gap feedback & $\tau_{x}$ & -0.47 & {$[-0.79 /-0.18]$} & -0.47 & {$[-0.79 /-0.18]$} \\
Std. Demand Shock & $\sigma_{r}\left(S_{t}\right)$ & 0.59 & {$[0.51-0.67]$} & 0.90 & {$[0.74-1.10]$} \\
Std. Supply Shock & $\sigma_{u}\left(S_{t}\right)$ & 0.83 & {$[0.73-0.94]$} & 1.00 & {$[0.83-1.24]$} \\
Std. MP Shock & $\sigma_{\varepsilon}\left(S_{t}\right)$ & 0.75 & {$[0.65-0.86]$} & 1.3 & {$[1.07-1.57]$} \\
Std. FP Shock & $\sigma_{\eta}$ & 0.64 & {$[0.57-0.71]$} & 0.64 & {$[0.57-0.71]$} \\
Autoregr. coeff. $r_{t}^{N}$ & $\rho_{r}$ & 0.85 & {$[0.75-0.931]$} & 0.85 & {$[0.75-0.93]$} \\
Autoregr. coeff. $u_{t}$ & $\rho_{u}$ & 0.42 & {$[0.28-0.57]$} & 0.42 & {$[0.28-0.57]$} \\
Constant Gain & $\bar{g}$ & 0.0517 & {$[0.048-0.054]$} & 0.0517 & {$[0.048-0.054]$} \\
\hline \hline
\end{tabular}

Table 4 - Posterior Estimates: Partisan Affiliation Federal Reserve's Chairman $\left(S_{t}=1\right.$ if the Chairman is Democrat, $S_{t}=0$ if the Chairman is Republican). The table displays the posterior mean estimates across regimes and the $95 \%$ posterior probability intervals. 


\begin{tabular}{|l|c|c|c|c|c|}
\hline \hline Same Party/Pre-elect. & & \multicolumn{4}{|c|}{ Posterior Distribution } \\
\hline & & \multicolumn{2}{|c|}{$S_{t}=0$} & \multicolumn{2}{|c|}{$S_{t}=1$} \\
\hline Description & Parameter & Mean & $95 \%$ PPI & Mean & $95 \%$ PPI \\
\hline Inverse IES & $\sigma^{-1}$ & 7.517 & {$[5.37-10.29]$} & 7.517 & {$[5.37-10.29]$} \\
Discount Factor & $\beta$ & 0.99 & - & 0.99 & - \\
Slope PC & $\kappa\left(S_{t}\right)$ & 0.074 & {$[0.016-0.16]$} & 0.042 & {$[0.005-0.116]$} \\
Inflation Target & $\pi^{*}\left(S_{t}\right)$ & 2.49 & {$[0.57-4.45]$} & 3.20 & {$[1.13-5.20]$} \\
MP Inertia & $\rho_{M P}\left(S_{t}\right)$ & 0.89 & {$[0.82-0.94]$} & 0.95 & {$[0.87-0.99]$} \\
MP Inflation feedback & $\chi_{\pi}\left(S_{t}\right)$ & 1.47 & {$[1.06-1.93]$} & 1.29 & {$[0.68-1.83]$} \\
MP Output Gap feedback & $\chi_{x}\left(S_{t}\right)$ & 0.33 & {$[-0.08-0.79]$} & 0.56 & {$[0.09-1.06]$} \\
FP Inertia & $\rho_{F P}$ & 0.88 & {$[0.81-0.98]$} & 0.88 & {$[0.81-0.98]$} \\
Budget Deficit Target & $\tau_{0}$ & -0.65 & {$[-1.64-0.33]$} & -0.65 & {$[-1.64-0.33]$} \\
FP Debt feedback & $\tau_{B}$ & 0.017 & {$[-0.02-0.06]$} & 0.017 & {$[-0.02-0.06]$} \\
FP Output Gap feedback & $\tau_{x}$ & -0.46 & {$[-0.76 /-0.2]$} & -0.46 & {$[-0.76 /-0.2]$} \\
Std. Demand Shock & $\sigma_{r}\left(S_{t}\right)$ & 0.62 & {$[0.54-0.71]$} & 0.57 & {$[0.47-0.79]$} \\
Std. Supply Shock & $\sigma_{u}\left(S_{t}\right)$ & 0.87 & {$[0.76-0.99]$} & 0.89 & {$[0.73-1.11]$} \\
Std. MP Shock & $\sigma_{\varepsilon}\left(S_{t}\right)$ & 0.99 & {$[0.87-1.13]$} & 1.03 & {$[0.85-1.26]$} \\
Std. FP Shock & $\sigma_{\eta}$ & 0.63 & {$[0.57-0.71]$} & 0.63 & {$[0.57-0.71]$} \\
Autoregr. coeff. $r_{t}^{N}$ & $\rho_{r}$ & 0.84 & {$[0.76-0.92]$} & 0.84 & {$[0.76-0.92]$} \\
Autoregr. coeff. $u_{t}$ & $\rho_{u}$ & 0.4 & {$[0.25-0.55]$} & 0.4 & {$[0.25-0.55]$} \\
Constant Gain & $\bar{g}$ & 0.0579 & {$[0.055-0.061]$} & 0.0579 & {$[0.055-0.061]$} \\
\hline \hline
\end{tabular}

Table 5 - Posterior Estimates: Regime is $S_{t}=1$ if the President and the Fed's Chairman share Party affiliation in pre-election quarters, $S_{t}=0$ if they are from different Parties or in a non-election quarter. The table displays the posterior mean estimates across regimes and the $95 \%$ posterior probability intervals. 


\begin{tabular}{|l|c|c|c|c|}
\hline & Pre/Post Elect. & Rep/Dem Pres. & Rep/Dem Fed's Chairman & Same Party+Pre-Elect. \\
\hline Log MargL & -785.67 & -818.64 & -794.22 & -790.83 \\
\hline
\end{tabular}

Table 6 - Model Comparison: Models' Marginal Likelihoods computed using Geweke's Harmonic Mean Approximation. 


\begin{tabular}{|l|c|c|c|c|c|}
\hline \hline Pre vs. Post-ELECTION & & \multicolumn{4}{|c|}{ Posterior Distribution } \\
\hline & & \multicolumn{2}{|c|}{$S_{t}=0$} & \multicolumn{2}{|c|}{$S_{t}=1$} \\
\hline Description & Parameter & Mean & $95 \%$ PPI & Mean & $95 \%$ PPI \\
\hline Inverse IES & $\sigma^{-1}$ & 6.22 & {$[4.12-9.19]$} & 6.22 & {$[4.12-9.19]$} \\
Discount Factor & $\beta$ & 0.99 & - & 0.99 & - \\
Slope PC & $\kappa\left(S_{t}\right)$ & 0.127 & {$[0.02-0.31]$} & 0.096 & {$[0.014-0.24]$} \\
Inflation Target & $\pi^{*}\left(S_{t}\right)$ & 2.44 & {$[0.5-4.31]$} & 2.57 & {$[0.65-4.47]$} \\
MP Inertia & $\rho_{M P}\left(S_{t}\right)$ & 0.88 & {$[0.79-0.95]$} & 0.92 & {$[0.83-0.99]$} \\
MP Inflation feedback & $\chi_{\pi}\left(S_{t}\right)$ & 1.35 & {$[0.88-1.81]$} & 1.31 & {$[0.88-1.81]$} \\
MP Output Gap feedback & $\chi_{x}\left(S_{t}\right)$ & 0.44 & {$[0.02-0.91]$} & 0.84 & {$[0.27-1.34]$} \\
FP Inertia & $\rho_{F P}\left(S_{t}\right)$ & 0.77 & {$[0.61-0.92]$} & 0.88 & {$[0.73-0.98]$} \\
Budget Deficit Target & $\tau_{0}\left(S_{t}\right)$ & -0.88 & {$[-1.71 /-0.17]$} & -1.18 & {$[-2.15 /-0.23]$} \\
FP Debt feedback & $\tau_{B}\left(S_{t}\right)$ & -0.01 & {$[-0.08-0.06]$} & 0.015 & {$[-0.07-0.1]$} \\
FP Output Gap feedback & $\tau_{x}\left(S_{t}\right)$ & -0.816 & {$[-1.25 /-0.3]$} & -0.822 & {$[-1.29 /-0.24]$} \\
Std. Demand Shock & $\sigma_{r}\left(S_{t}\right)$ & 0.47 & {$[0.37-0.58]$} & 0.43 & {$[0.33-0.54]$} \\
Std. Supply Shock & $\sigma_{u}\left(S_{t}\right)$ & 0.67 & {$[0.55-0.81]$} & 0.93 & {$[0.73-1.19]$} \\
Std. MP Shock & $\sigma_{\varepsilon}\left(S_{t}\right)$ & 0.48 & {$[0.39-0.58]$} & 0.44 & {$[0.34-0.56]$} \\
Std. FP Shock & $\sigma_{\eta}\left(S_{t}\right)$ & 0.53 & {$[0.43-0.66]$} & 0.45 & {$[0.35-0.58]$} \\
Autoregr. coeff. $r_{t}^{N}$ & $\rho_{r}$ & 0.8 & {$[0.66-0.92]$} & 0.8 & {$[0.66-0.92]$} \\
Autoregr. coeff. $u_{t}$ & $\rho_{u}$ & 0.77 & {$[0.64-0.9]$} & 0.77 & {$[0.64-0.9]$} \\
Constant Gain & $\overline{\mathrm{g}}$ & 0.061 & {$[0.055-0.067]$} & 0.061 & {$[0.055-0.067]$} \\
\hline \hline
\end{tabular}

Table 7 - Posterior Estimates: Post-1985 Sample, Pre-Election vs. Post-Election Regime. The table displays the posterior mean estimates across regimes and the $95 \%$ posterior probability intervals. 

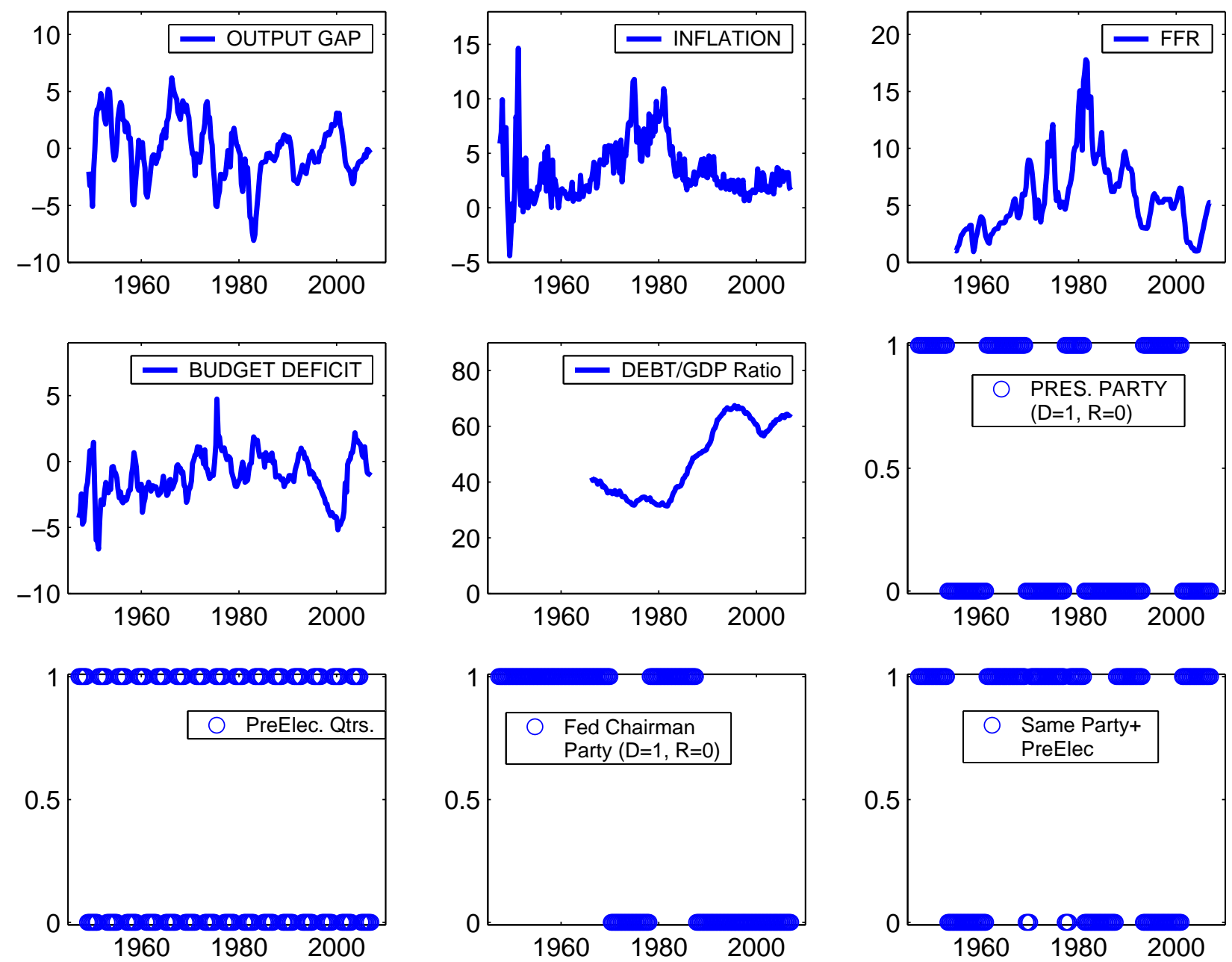

Figure 1: Data Series. 

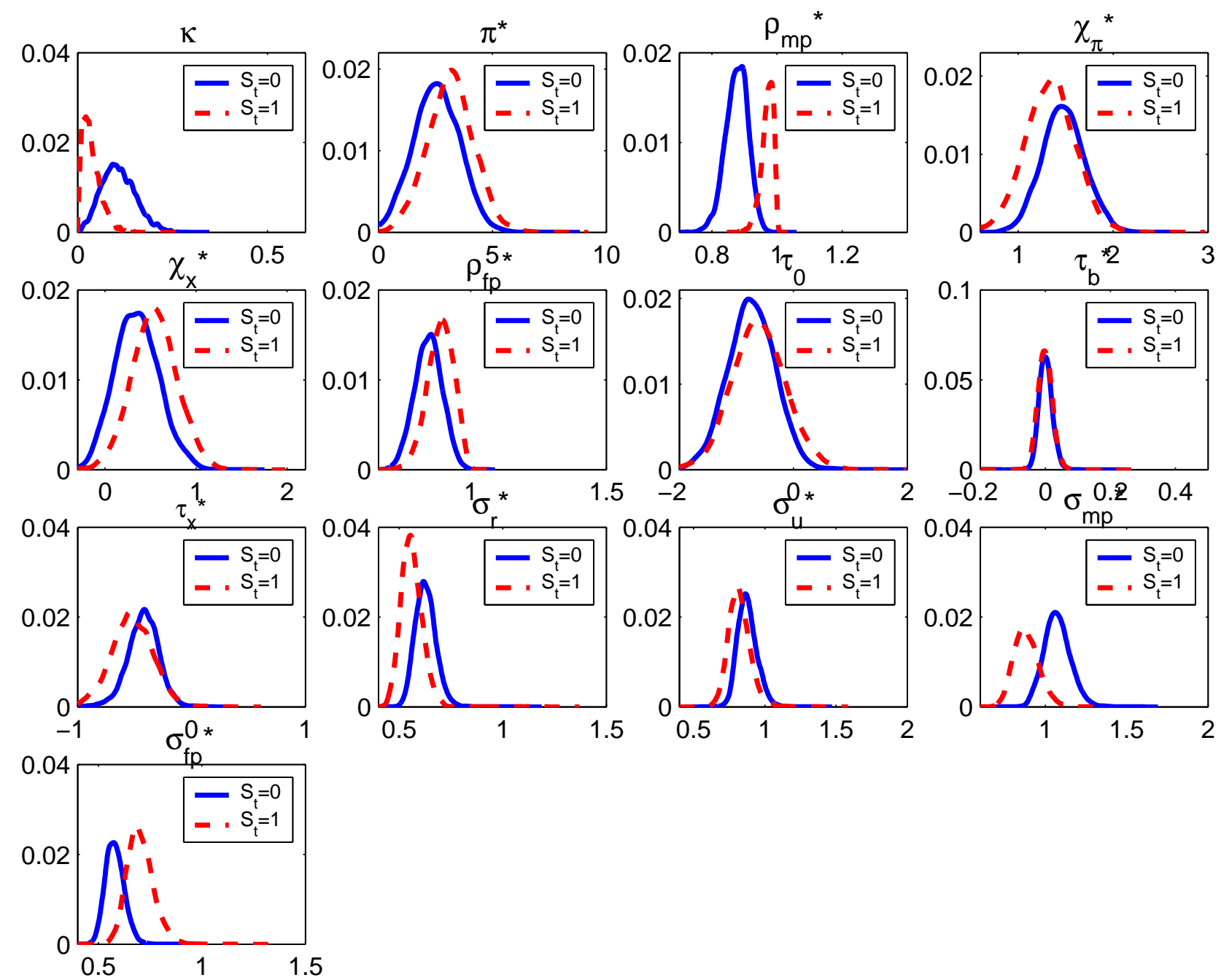

Figure 2: Posterior Distributions: Pre-Election vs. Post-Election Regime. 

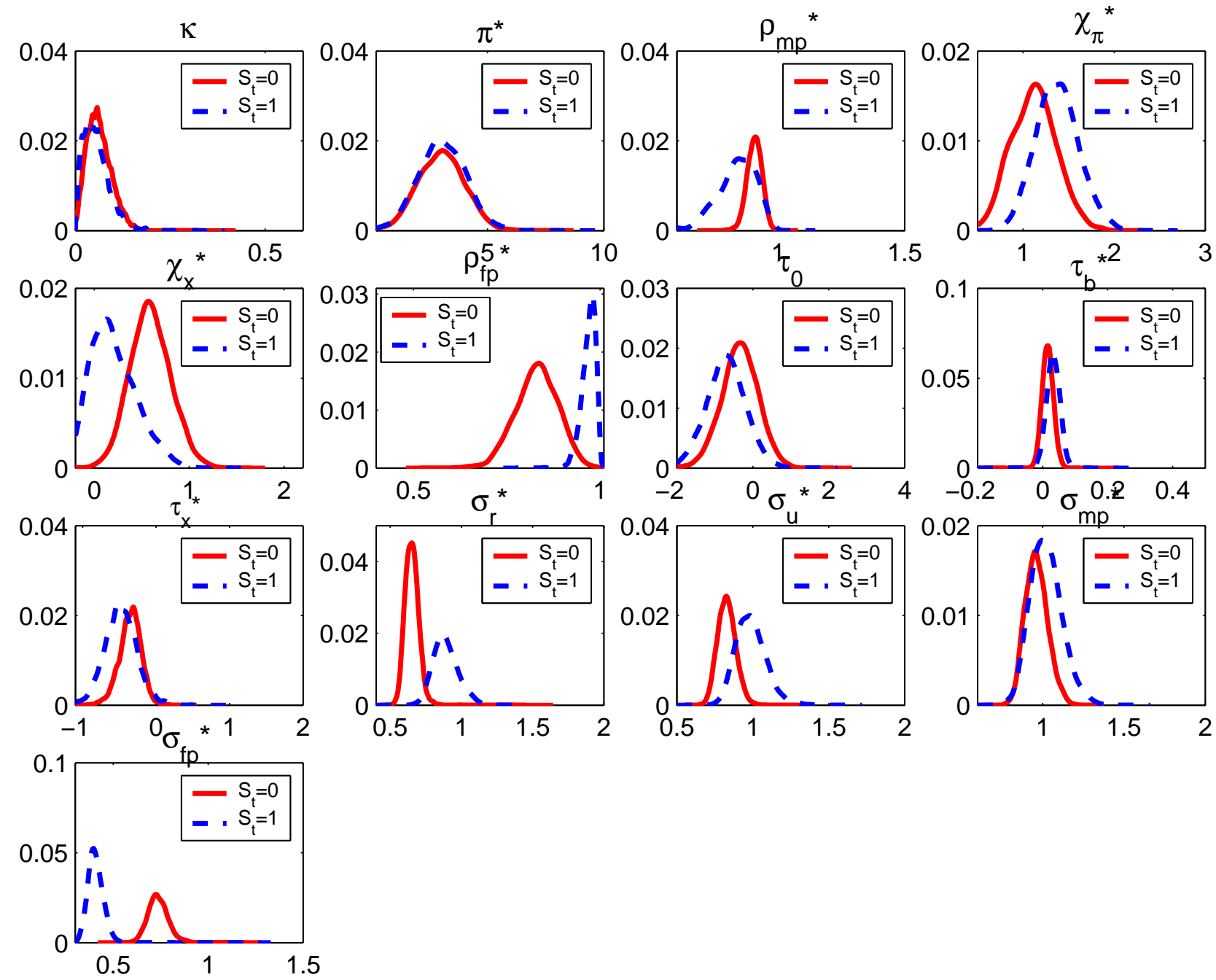

Figure 3: Posterior Distributions: Regime given by Presidential Party. 

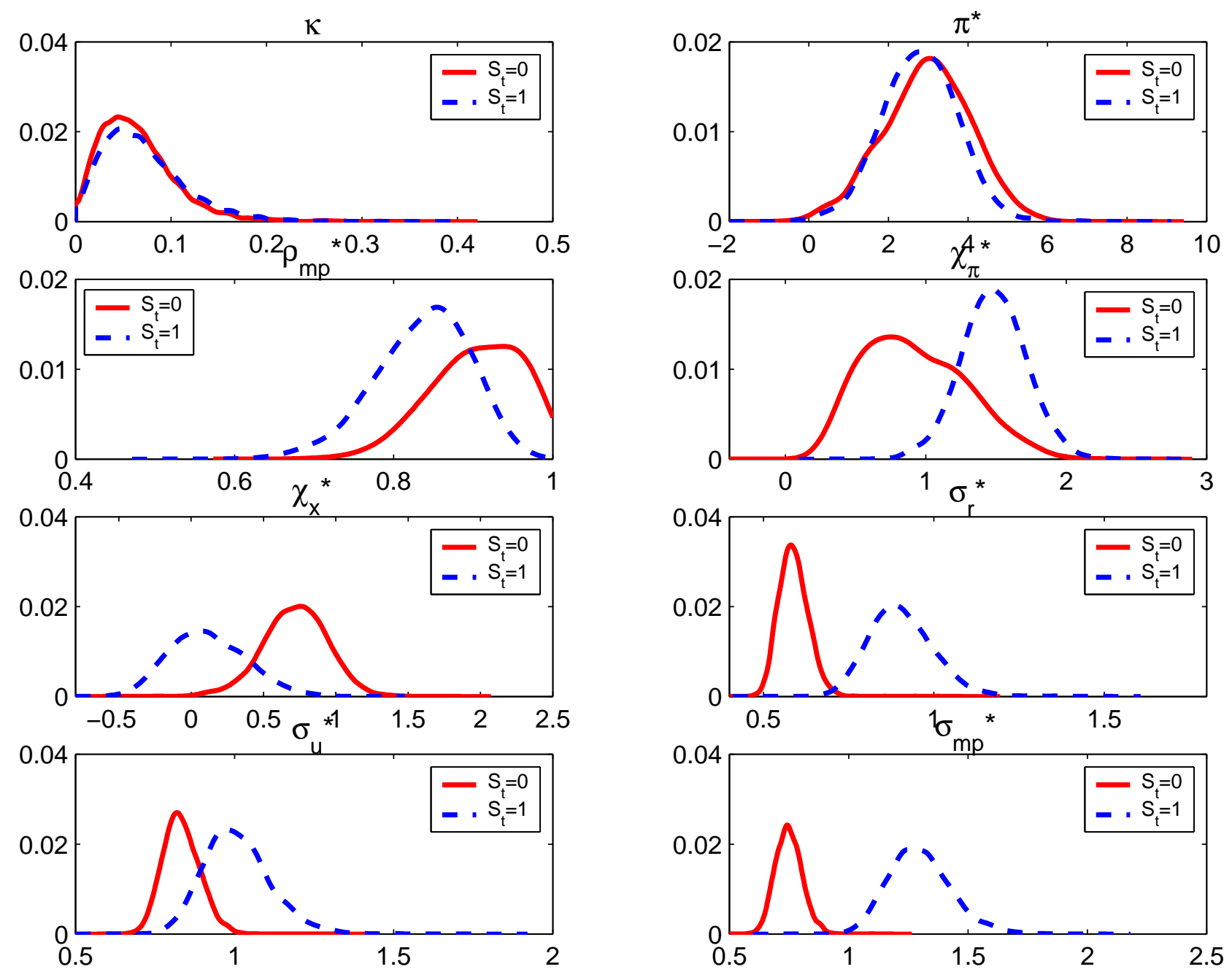

Figure 4: Posterior Distributions: Regime given by Fed Chairman's Party. 

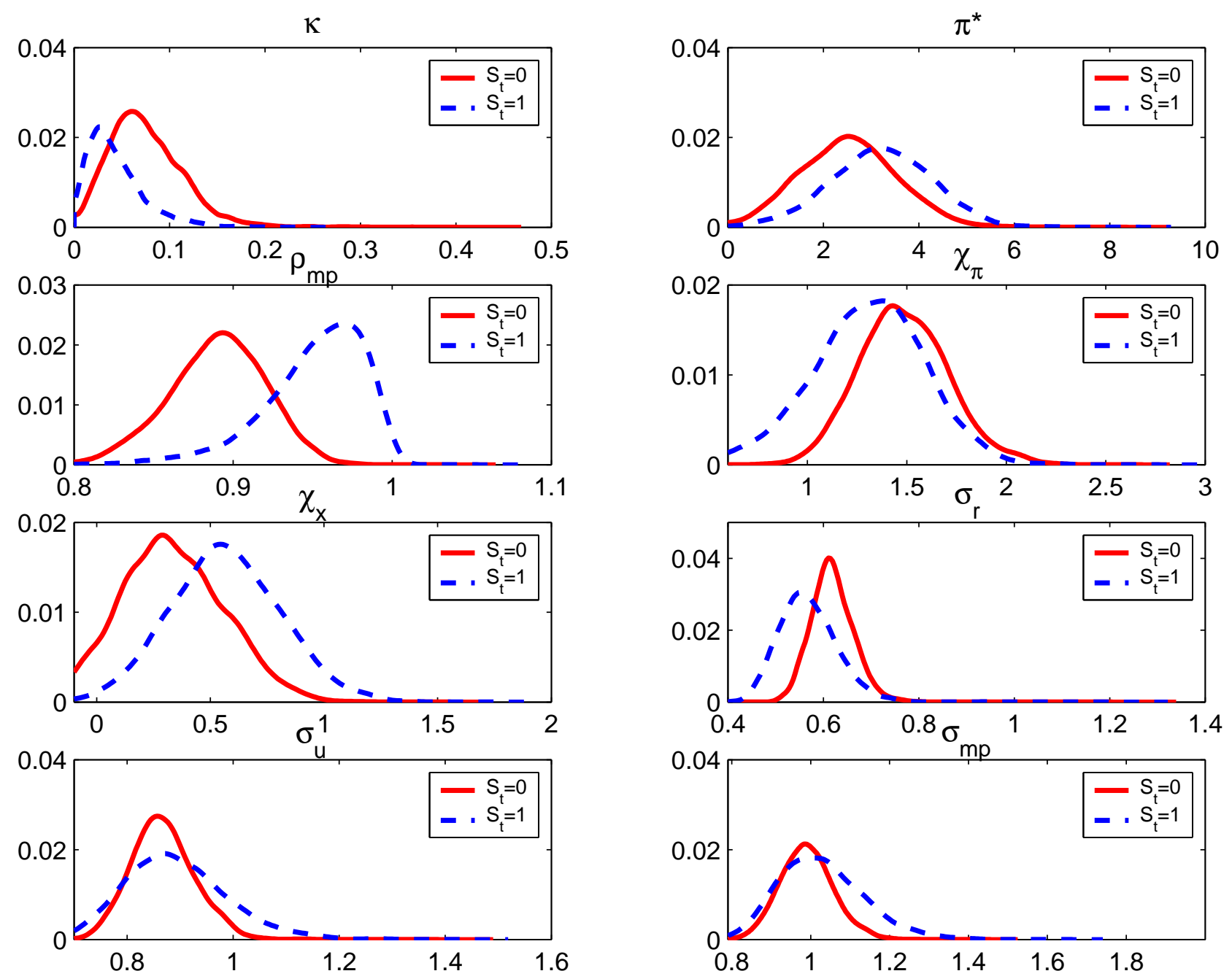

Figure 5: Posterior Distributions: Pre-Election quarters when President and Fed Chairman share Party Affiliation. 


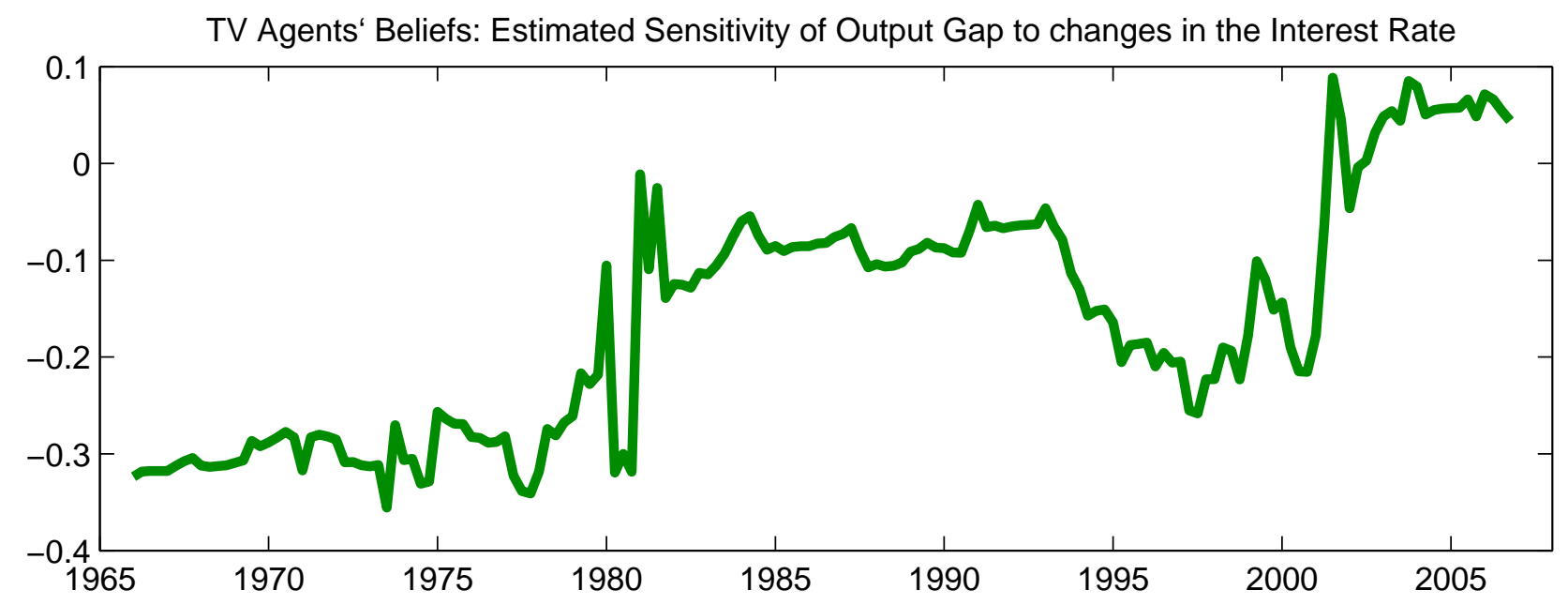

TV Agents' Beliefs: Estimated Autoregressive Coefficient in Inflation

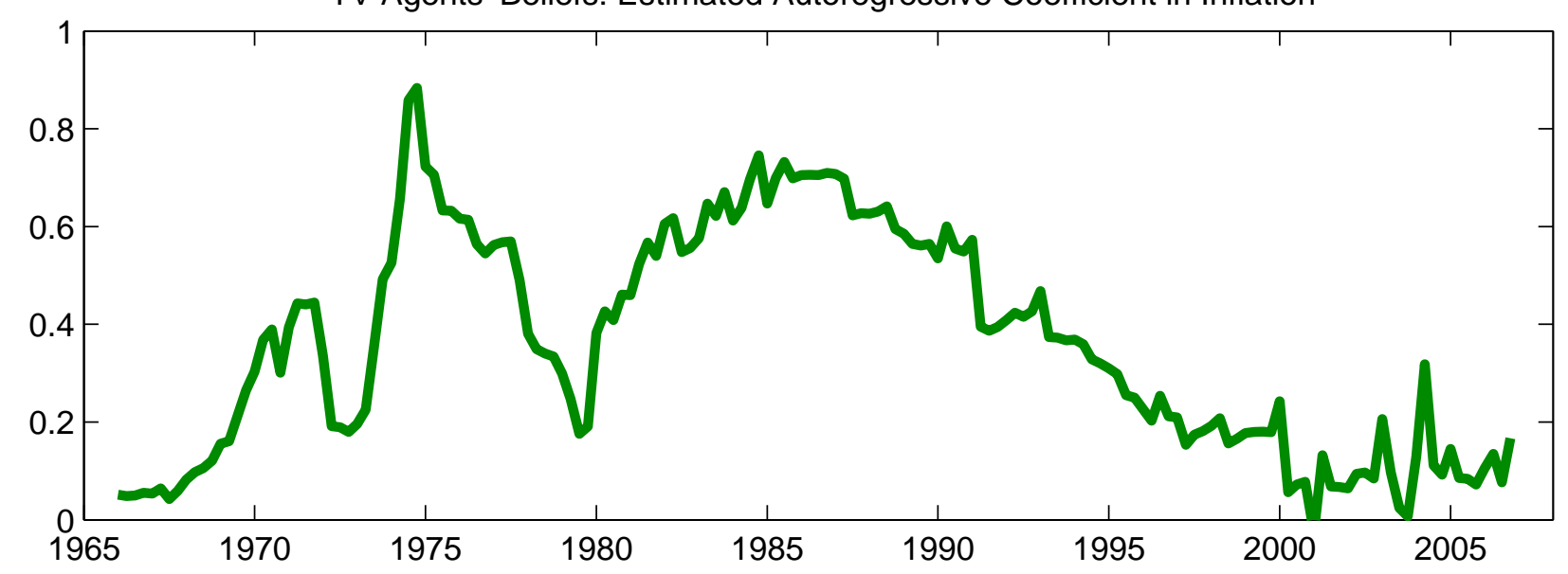

Figure 6: Selected Beliefs. 

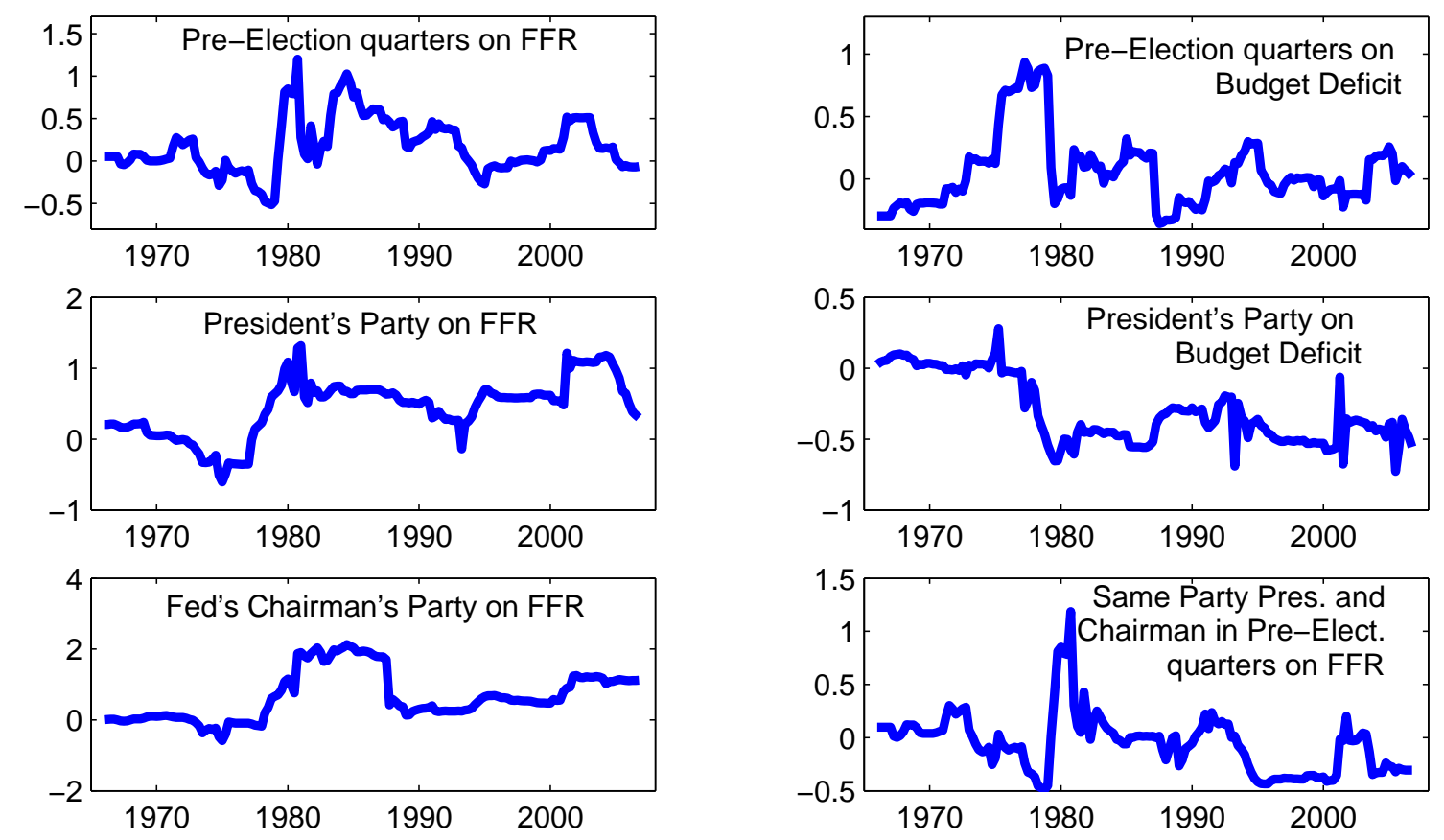

Figure 7: Selected Beliefs. 
Differences in Monetary Policy due to Pre-Election Periods

(Positive deviations mean more expansionary policies before elections)

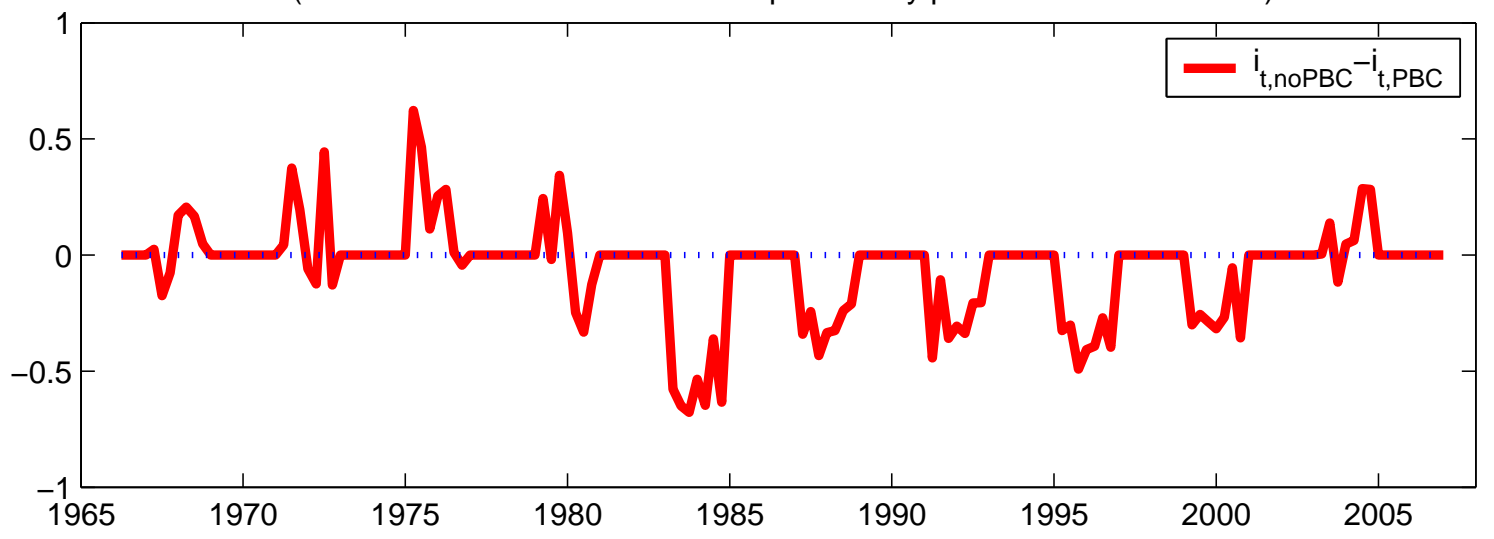

Differences in Fiscal Policy due to Pre-Election Periods (Positive deviations mean more expansionary policies before elections)

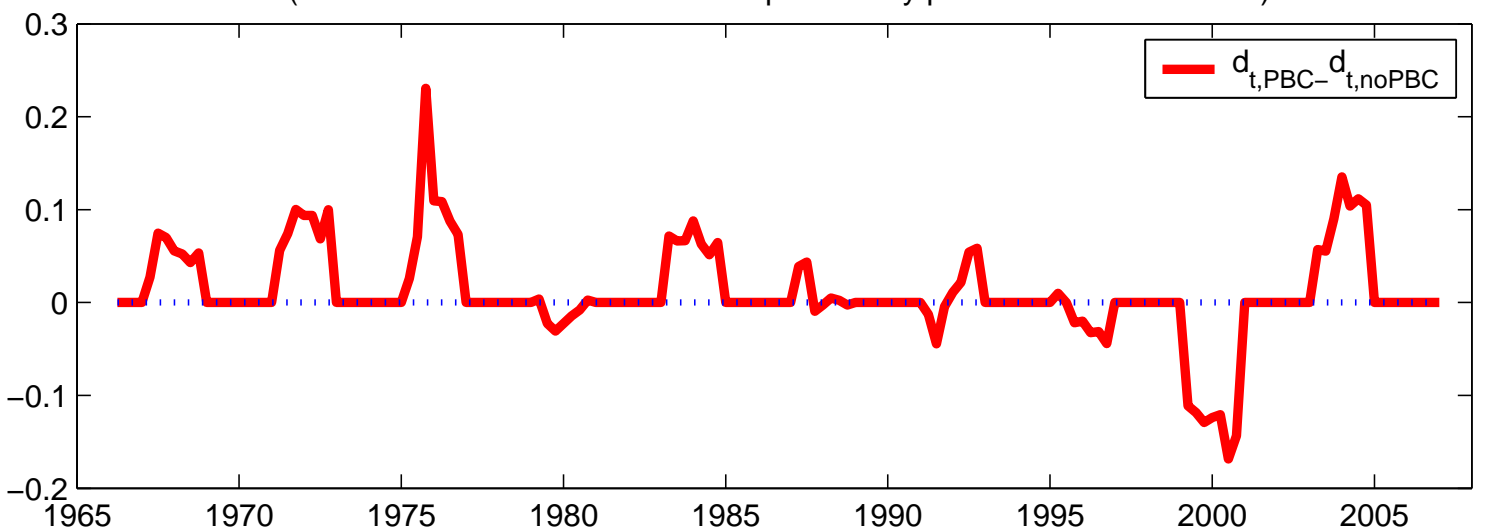

Figure 8: Differences in Monetary and Fiscal Policies in Pre-Election Periods. The table compares interest rates and budget deficits implied by policy rules with and without political effects. 

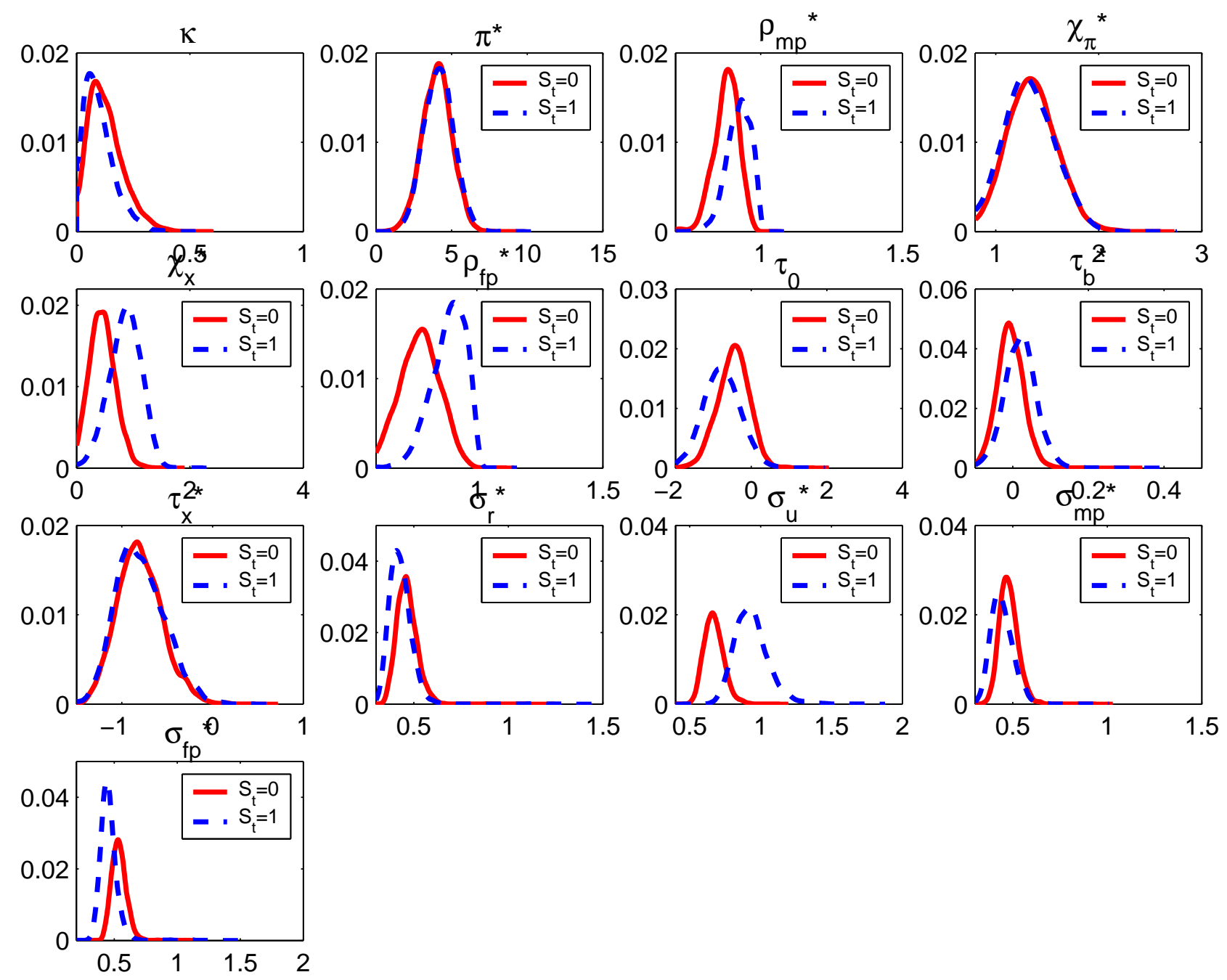

Figure 9: Posterior Distributions: Post-1985 Sample, Pre-Election vs. Post-Election Regime. 